TESTING THE ROLE OF SOURCE CREDIBILITY ON MEMORY FOR INFERENCES

\author{
A Dissertation \\ by \\ JIMMEKA JOY GUILLORY
}

\begin{abstract}
Submitted to the Office of Graduate Studies of Texas A\&M University in partial fulfillment of the requirements for the degree of

DOCTOR OF PHILOSOPHY
\end{abstract}

August 2011

Major Subject: Psychology 
Testing the Role of Source Credibility on Memory for Inferences Copyright 2011 Jimmeka Joy Guillory 


\title{
TESTING THE ROLE OF SOURCE CREDIBILITY ON MEMORY FOR INFERENCES
}

\author{
A Dissertation \\ by \\ JIMMEKA JOY GUILLORY
}

\begin{abstract}
Submitted to the Office of Graduate Studies of
Texas A\&M University

in partial fulfillment of the requirements for the degree of

DOCTOR OF PHILOSOPHY
\end{abstract}

Approved by:

$\begin{array}{ll}\text { Chair of Committee, } & \text { Lisa Geraci } \\ \text { Committee Members, } & \begin{array}{l}\text { Steven Smith } \\ \text { Jyotsna Vaid } \\ \text { Evan Stephen }\end{array} \\ \text { Head of Department, } & \text { Ludy Benjamin }\end{array}$

August 2011

Major Subject: Psychology 


\begin{abstract}
Testing the Role of Source Credibility on Memory for Inferences. (August 2011) Jimmeka Joy Guillory, B.S., M.S., Texas A\&M University

Chair of Advisory Committee: Dr. Lisa Geraci
\end{abstract}

Research shows that people have difficulty forgetting inferences they make after reading a passage, even when the information that the inferences are based on is later known to be untrue. This dissertation examined the effects of these inferences on memory for political information and tested if the credibility of the source of the correction influences whether people use the correction, or continue relying on the original information when making inferences. According to source credibility theory, there are two main factors that contribute to credibility, expertise and trustworthiness. Experiment 1 examined credibility as a function of both expertise and trustworthiness. The results from this experiment showed that having a correction from a source who is high on both factors significantly decreased the use of the original information. Experiment 2 examined credibility as a function of expertise. The Experiment 2 results showed no significant decrease in participants' use of the original information, if a correction came from a source that was simply more expert (but not more trustworthy) than another source. This finding suggests that source expertise alone is not sufficient to reduce reliance on the original information. Experiment 3, which examined credibility as a function of trustworthiness, demonstrated that having a highly trustworthy source does 
significantly decrease the use of the original information when making inferences. This study is the first to provide direct support for the hypothesis that making the source of a correction more believable decreases use of the original discredited information when making inferences. 


\section{ACKNOWLEDGEMENTS}

I would like to thank my committee chair, Dr. Lisa Geraci, and my committee members, Dr. Steve Smith, Dr. Jyotsna Vaid, and Dr. Evan Parker-Stephen, for their guidance and support throughout the course of this research.

Thanks also go to my colleagues and the psychology department faculty and staff for making my time at Texas A\&M University a great experience. I also want to extend my gratitude to all of the students who were willing to participate in the study. Finally, thanks to my mother and father for their encouragement and love. 
TABLE OF CONTENTS

Page

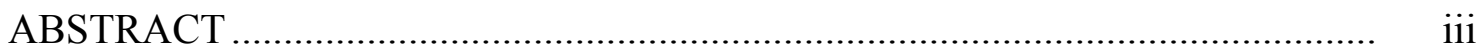

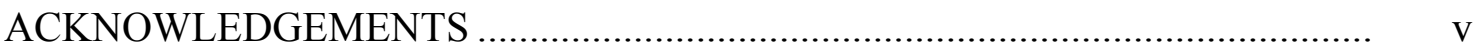

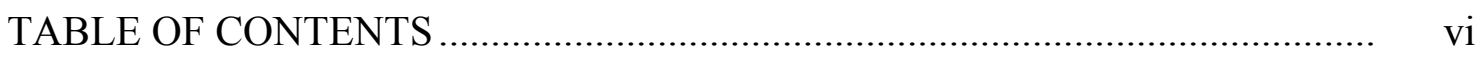

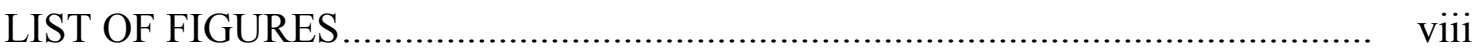

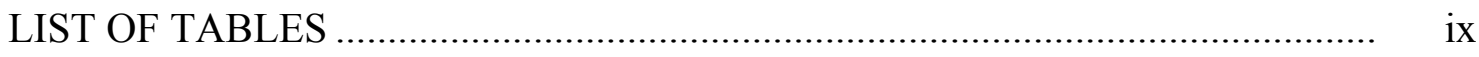

1. INTRODUCTION: THE EFFECTS OF INFERENCES ON MEMORY .......... 1

2. EXAMINING INFERENCES IN MULTIPLE DOMAINS................................ 10

2.1 Politics......................................................... 10

2.2 Courtroom …….............................................................. 11

2.3 Medical Decision Making ............................................................. 19

2.4 Marketing ................................................. 22

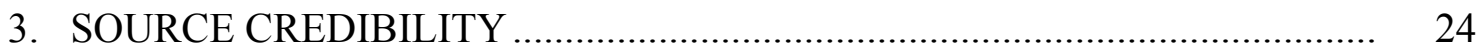

4. RESEARCH DESIGN AND METHODS ………............................................ 27

4.1 Credibility Norming...................................... 27

4.2 Experiment 1 Method............................................................ 28

4.3 Experiment 2 Method............................................................... 33

4.4 Experiment 3 Method.................................................................. 33

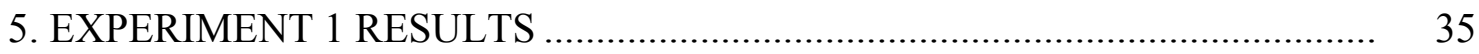

5.1 Recall and Questionnaire................................... 35

5.2 Additional Tests ...................................................................... 42

6. EXPERIMENT 2 RESULTS ................................................................... 48

6.1 Recall and Questionnaire.................................... 48 
6.2 Additional Tests ............................................................... 55

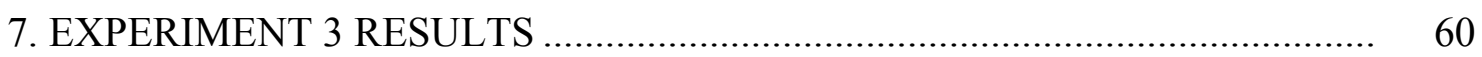

7.1 Recall and Questionnaire.................................. 60

7.2 Additional Tests ................................................................ 66

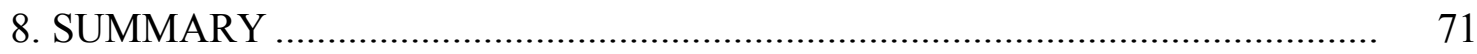

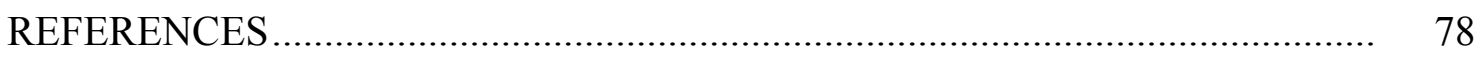

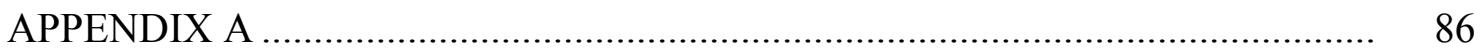

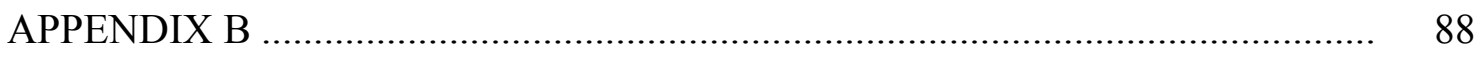

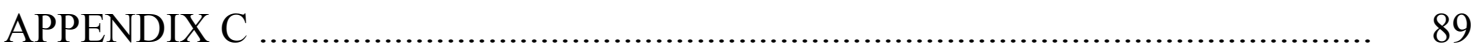

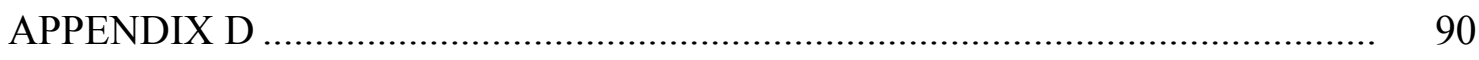

VITA 


\section{LIST OF FIGURES}

FIGURE Page

$1 \quad$ Exp 1: Free recall of original message and correction ........................... 36

$2 \quad$ Exp 1: Remember/know/believe judgments for factual questions ........... 39

3 Exp 1: Remember/know/believe judgments for inference questions........ 40

$4 \quad$ Exp 1: Confidence judgments for factual questions............................... 41

$5 \quad$ Exp 1: Confidence judgments for inference questions.......................... 41

$6 \quad$ Exp 1: Participants use of original information by paranoia scores.......... 46

$7 \quad$ Exp 2: Free recall of original message and correction ........................... 49

$8 \quad$ Exp 2: Remember/know/believe judgments for factual questions ............ 52

$9 \quad$ Exp 2: Remember/know/believe judgments for inference questions........ 53

10 Exp 2: Confidence judgments for factual questions............................ 54

11 Exp 2: Confidence judgments for inference questions........................... 54

12 Exp 3: Free recall of original message and correction ........................... 61

13 Exp 3: Remember/know/believe judgments for factual questions............ 63

14 Exp 3: Remember/know/believe judgments for inference questions........ 64

15 Exp 3: Confidence judgments for factual questions............................. 65

16 Exp 3: Confidence judgments for inference questions........................... 65 


\section{LIST OF TABLES}

TABLE Page

1 Norming means for the source of the correction statement ..................... 28

$2 \quad$ Exp 1: Reasons given for correction .............................................. 43

$3 \quad$ Exp 2: Reasons given for correction ............................................... 56

$4 \quad$ Exp 2: Credibility, expertise, \& trustworthiness ratings ….................... 58

$5 \quad$ Exp 3: Reasons given for correction ............................................... 67

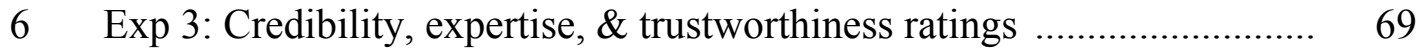




\section{INTRODUCTION: THE EFFECTS OF INFERENCES ON MEMORY}

Many real world examples and laboratory studies have shown that people have a difficult time forgetting the inferences they make, even after the information that the inferences are based on has been shown to be untrue (see Seifert, 2002, for a review). For example, not long ago the media reported an exaggerated story about the link between vaccines and autism. This report sparked many parents to attribute suspected cases of autism to prior vaccines and others to refuse many essential childhood vaccinations. There have since been several reports showing failures to find a connection between vaccines and autism. It is also clear now that the original report was based on faulty data. Upon discovering that the original study by Andrew Wakefield was improperly conducted, leading to erroneous conclusions, the British General Medical Council (GMC) stripped Wakefield of his license to practice medicine (Triggle, 2010). Multiple public service announcements have been released to correct this information and to urge parents to vaccinate their children, yet parents continue to believe that vaccines may cause autism and have chosen not to vaccinate their children (BaronCohen, 2009). Parent's refusal of vaccines has had devastating consequences. Now, there is a rise in childhood deaths associated with previously eradicated diseases, such as measles and mumps.

Laboratory research also shows that people have difficulty forgetting information they are told, even after that erroneous information is corrected (Wilkes \&

This dissertation follows the style of Psychonomic Bulletin \& Review. 
Leatherbarrow, 1988; Johnson \& Seifert 1994; Wilkes \& Reynolds, 1999; Guillory \& Geraci 2010). In the basic paradigm, participants are given a story to read and some piece of critical information is corrected towards the end of the account. For example, in the original Wilkes and Leatherbarrow (1988) study, participants heard about a fire in progress, in one instance, and were told that, "cans of oil paint and gas cylinders" had been stored in a room where the fire started. Later messages referred to "oily smoke and sheets of flame", "explosions", and "toxic fumes" as features of the fire. Later still, participants read a message stating a correction, which indicated that no paint or gas cylinders had been in the storage room. Results showed that participants recalled the correction statement indicating that the storage room did not have any gas or paint, but was instead empty. However, when asked for a possible cause of the toxic fumes, participants responded using the inference based on the original information provided by the report, that paint and gas cylinders were a possible cause of the fire. Results using this general paradigm have shown that participants continue to rely on the old information when making inferences even though they clearly recalled that the information had been corrected. The fact that participants continue to rely on the original, but corrected, information, is surprising given the fact that they are able to explicitly state that the information has been corrected. Thus, it appears that once people hear a piece of information, they will continue to draw upon this information to make inferences. This happens despite the explicit knowledge that the original information is incorrect. It is important to note that participants rely on the original corrected information only when making inferences and not when answering factual questions. 
This suggests that inferences, in particular, that are drawn from the original information are powerful sources of information that may be elusive and difficult to change.

Although the persistence of inferences in memory has been demonstrated in a growing number of previous studies (Wilkes \& Leatherbarrow 1988; Johnson \& Seifert 1994, 1999; Wilkes \& Reynolds, 1999; Guillory \& Geraci 2010), researchers have yet to explain why people continue to believe their erroneous inferences in the face of counter information. According to one theory, inferences persist in memory because people fail to edit their memories (Wilkes \& Leatherbarrow, 1988). In particular, this theory suggests that people make elaborative inferences during reading before the correction occurs. Due to a failure in editing, these inferences appear to outlast the discrediting of the initial information. However, some findings are inconsistent with this theory. For example, results show that participants continue to make incorrect inferences even when the correction is provided immediately after the misinformation, presumably before the participants make the original inference during reading (Johnson \& Seifert, 1994). This finding suggests that inferences persist even if the participants have the opportunity to edit their inferences early in the experiment. Alternatively, participants may make inferences automatically upon reading the information, and so an immediate correction may not have an effect on participants' inferences.

Accessibility theory states that the mere presence of information in memory may lead people to incorporate it into later reasoning. If information is available in memory, regardless of its status, it may affect the conclusions that people draw (Tversky \& Kahneman, 1973). As a test of this theory, after reading the correction, participants were 
asked to generate their own possible alternative explanations (Johnson \& Seifert, 1999). The authors proposed that if the mere availability of information in memory results in its use, people should be able to rely on the alternate causes they generated. However, the results showed that generating alternatives did not decrease the likelihood of mentioning the corrected misinformation as an answer to the inference questions, suggesting that the availability of the alternate causes in memory was not enough for it to be incorporated into later reasoning when answering the inference questions.

Alternatively, researchers have suggested that inferences persist because participants are not given alternate explanations of the cause of the fire (Johnson \& Seifert; 1994, 1999). In the absence of alternative explanations, participants may choose to ignore the reported inaccuracy and consider the causal story as "too good not to be true" (Seifert, 2002). The idea is that presenting a good explanation and subsequently ruling it out, leaves a gap in understanding, which may cause people to have difficulty understanding the story unless an alternative explanation is presented (Seifert, 2002). In a test of this theory, participants were given plausible and causal alternatives to the misinformation (Johnson \& Seifert, 1994). The results showed that providing these alternatives reduced participants' use of the original information. However, some influence of the discredited information still remained noticeable. The authors concluded that the influence of old information cannot be completely erased. Van Oostendorp and Bonebakker (1999) attempted to determine the cause of the incomplete updating of the correction. To do this they first adapted the reading materials so that in the control condition the correct information is provided at the same (late) stage that it appears in 
the correction conditions. In the previous control conditions, the correct information was presented early in the story so, many messages could be immediately interpreted from the right perspective, whereas subjects in the correction condition had to re-interpret these messages in retrospect. In this study the authors also planned to replicate the results that Johnson and Seifert found concerning the influence of the alternative causal explanation. The results of this study showed that when compared to Wilkes and Leatherbarrow and Johnson and Seifert, they found fewer references to the old information, however the effect was still not eradicated. The authors concluded that they may have gotten better results than previous studies because of the explicitness of their correction and the participants' processing strategies. This study used a correction that was much more explicit than in previous studies, which included a direct statement that said, "the previous message had been incorrect". Also, this study used a within-subjects design instead of a between subjects design, so the participants were exposed to four different news stories and answered inference questions after reading each one. The authors believe that this may have resulted in more extensive and thorough processing of the information because the participants knew in advance that they would be answering inference questions so they may have paid more attention when reading the text, which may have lead to deeper processing, compared to previous participants. In a subsequent experiment van Oostendorp and Bonebakker tried to restrict processing time by presenting the stories orally on tape. The results showed that participants performed more poorly on the factual questions than they did in the first experiment. This can be attributed to the oral presentation of the story, which restricted presentation time and 
processing. However, oral presentation did not lead to increased use of the old information. So, they were able to conclude that the level of processing is probably not what caused reduced use of the original information, so the change in design (withinsubjects instead of between-subjects) is probably not what affected the results. The authors also did not find differences between the typical experimental condition and their alternative causal explanation condition. The participants continued to use the old information the same amount in both conditions, so they were not able to replicate the findings of Johnson and Seifert (1994). Therefore, the reduced use of the original information can most likely be attributed to the explicitness of the correction. The authors conclude with the belief that the more adequate controls used in their study actually give more strength to the conclusions drawn from Wilkes and Leatherbarrow and Johnson and Seifert. Despite all of the additional controls used in this study, there was still a significant influence of the old information. In summary, the van Oostendorp and Bonebakker (1999) study demonstrated that a correction cannot easily eliminate the influence of misinformation, whether presented in written form or orally. Also, neither a repeated correction nor an alternative explanation can undo the effect of the original information.

In an earlier study, van Oostendorp (1996) examined participants' ability to update their situation models while reading newspaper articles. In his study, van Oostendorp found that participants were able to update "low-relevance" information better than "high relevance" information (high relevance information was central to understanding the text, while low relevance information refers to information that simply 
verified details of the situation), and this finding was not affected by instruction to read carefully or a one day delay. He also found that it was more difficult for participants with a high interest (in the topic of the newspaper article) to update "high-relevance" information. The finding that it is generally more difficult to update "high-relevance" information compared to "low-relevance" information is supported by Johnson and Seifert (1994). Their findings suggest that a central and important piece of information will be harder to forget, if it is incorrect, compared to less important information. One possible reason for this finding is that salient information cannot easily be altered without discarding the entire theory (or situation model), but peripheral information can be altered while preserving the theory (Chinn \& Brewer, 1993). Another possible reason for this finding is "sloppy encoding" (van Oostendorp \& Bonebakker, 1999). This hypothesis suggests that participants encode the correction superficially because they erroneously think that they already know the information. This may what happened in the case of the "high-relevance" information. Previous research has also shown that context can influence readers' text comprehension. Garcia-Arista, Campanario, and Otero (1996) examined the influence of subject matter (context) on comprehension monitoring in secondary school students. The subjects were led to believe that they were reading passages from either a science textbook in a science class, or from a newspaper in a language class. Comprehension monitoring was expected to diminish in a situation in which the information was acquired from a scientific source, when compared to a situation in which the information was acquired from a less authoritative source like a newspaper. The comprehension monitoring was measured by analyzing students' 
responses to a questionnaire and their written recall of several contradictory texts. The results showed that comprehension and recall increased in the science setting in comparison to the newspaper setting. The authors proposed that they found better comprehension and recall in the science setting because comprehension monitoring is dependent on subject matter (context).

Van Oostendorp (1996) proposes that, in order to improve the likelihood of accurate correction in memory the correction message should, first, be directly stated and should reinstate the old information. Secondly, the correction message should optimally provide a causal alternative to the old information, that is, really explain the modification (Johnson \& Seifert, 1994; Van Oostendorp \& Bonebakker, 1999).

So, the most promising method for correcting erroneous inferences is to give people a plausible alternative to the original information (Johnson \& Seifert, 1994). One implicit assumption is that participants continue to believe the original message when there is no alternative because they think that the correction is simply a cover up to the truth. In Guillory and Geraci 2010, participants were asked to describe why they believed there was a correction in the story. The results showed that more than a third of the participants believed that the correction was a cover up for the truth. If participants do not believe the correction, they may continue to rely on inferences from the original, incorrect, message. In fact, to test for this possibility they examined the use of the original information for people who thought the correction was a mistake compared to those who believed it was a cover-up. Results showed that participants who thought the correction was a cover-up were slightly more likely to continue using the incorrect 
original message than participants who thought the correction was a mistake, though this difference was not significantly different. Thus, there is some preliminary evidence that participants may be able to overcome the persistence of erroneous inferences in memory if the correction comes from a credible source. The current study is designed to answer this question. One way to reduce the lingering memory effects of erroneous inferences might be to make the source of the correction more believable. To do this, I manipulated the source credibility of the correction as an attempt to overcome and explain the persistence of inferences in memory. Reducing the influence of inferences on beliefs and behavior has real world importance across many different domains. As a starting point, the current study examines the persistence of inferences in memory in the political domain. 


\section{EXAMINING INFERENCES IN MULTIPLE DOMAINS}

Why inferences persist in memory and how to reduce their effects on memory and behavior is important to understand not only for theoretical reasons, but also for practical reasons. In fact, the persistence of erroneous inferences is an important issue that plagues many domains of life.

\subsection{Politics}

For example, in politics, research shows that negative (smear) campaigns depress the publics' evaluation of the political opponent (Fridkin \& Kenney, 2004, 2008). In recent years, politicians have become aware of this and have taken measures to try to counter these negative campaigns, such as launching websites dedicated to fighting the false rumors. However, the laboratory research on memory for inferences suggests that, even if the information provided in these smear campaigns is corrected, voters may continue to believe the inferences they made about the candidate after hearing the initial false information. In fact, previous research has shown that even when people are given true information they may choose to disregard it because of their beliefs or preferences. One study gave a group of participants' factual information about welfare in America (Kuklinski, Quirk, Jerit, Schwieder, \& Rich, 2000). Then participants were asked questions about their policy preferences. The authors found that these participants held the same views about welfare as a control group who never received the welfare facts. Thus, the participants who were told the correct facts about welfare chose not to update their preferences accordingly. In a subsequent experiment, participants were asked to 
estimate the percent of the budget that goes to welfare, and what percent they thought should be spent on welfare. Then the participants were told the actual percentage of the budget that is spent on welfare, which was much lower than their estimates. The authors proposed that the participants were faced with a conflict, having just expressed their estimated and preferred levels of government spending and then being told that the actual percentage is much lower than their estimates. They hypothesized that if the purpose is to render a fact immediately salient, meaningful, and interpretable, this presentation should do it. The results showed that if the correct information is presented in a way that draws attention to incorrect beliefs and contrasts them with the truth, then the correct information can have a substantial effect on attitudes. This is an important finding because the participants in this study were confronted with information that corrected their personal beliefs, and the correct information was presented in such a way that allowed them to use it. However, it is unknown if the effects are long lasting.

\subsection{Courtroom}

The fact that people often continue to rely on incorrect information even when they have been given counter information is not only relevant for politics, it is also important when considering what goes on in a courtroom. For example, often jurors are told information and later told to "scratch that from memory". Given the research on memory for inferences, it is likely that jurors recall that the information was corrected but may not be able to ignore the inferences that they made about that information. Indeed, mock jury research shows that verdicts can be influenced by a wide range of nonevidentiary factors presented both inside and outside the courtroom (Kassin \& 
Studebaker, 1998); including testimony ruled inadmissible by the judge (Pickel, 1995; Sue, Smith, \& Caldwell, 1973; Thompson, Fong, \& Rosenhan, 1981; Wissler \& Saks, 1985).

In their study examining judges' ability to ignore inadmissible information, Wistrich, Guthrie, and Rachlinski (2005) cited three theories for why people have difficultly disregarding information. The theories mentioned are similar to those provided in Seifert (2002), but from different research traditions. The first theory is motivation. People who do not believe the information should be ignored are more likely to continue using it when making decisions and inferences about the information. Consistent with this theory, Guillory and Geraci (2010) found that participants who believed that the original information was true and that the correction was a "cover up" were more likely to continue using the incorrect original message compared to participants who thought the correction was correcting a mistake, although the difference in performance was not significant.

The second theory for why people may have difficulty disregarding information is the ironic process theory. This theory proposes that refraining from unwanted thoughts is so difficult that it can produce an "ironic process" in which people ultimately spend even more time thinking about thoughts they are trying to suppress (Wegner, 1994). When people attempt to suppress a thought, they monitor their mental activity to verify that they are suppressing it; however, doing so is actually keeping the thought more active in their memory. So in the continued influence of inferences studies participants may read the correction statement and refer back to the original statement to recall the 
information that should be corrected. When they do this they may actually be strengthening the original information in memory and that is what continues to influence them when they are making inferences.

The third theory for why people may have difficulty disregarding information is referred to as mental contamination. The type of mental contamination that is most suitable for the proposed study is belief perseverance. As the mind continues to dwell on "to be forgotten" information, it elaborates on the information and incorporates it into a belief system which affects subsequent information processing (Ross, Lepper, \& Hubbard, 1975). When people acquire new information they incorporate it into the knowledge that they already possess. Once this happens, they are likely to have difficulty undoing the beliefs that the original information inspired. One of the first studies on belief perseverance had undergraduates complete the task of evaluating ten suicide notes (Ross, Lepper, \& Hubbard, 1975). They were told that half of the notes were real and the other half were created for the study. Their task was to determine which of the notes were real and which were made up. Afterwards, the experimenters told some of the participants they performed well on the test and some of the participants were told that they performed poorly. Later, all of the participants were told that, in fact, all of the suicide letters were fakes. The participants then had to estimate how well they would perform on a real version of the task. The results showed that participants who had been told that they performed well indicated that they would do well on a real task, and participants who had been told they performed poorly indicated that they would do poorly. Even though all of the participants knew that the feedback they received wasn't 
based on fact, the beliefs they had formed about their capabilities persisted. This finding has important implications for the proposed study because even after participants read the correction statement they may continue to hold beliefs about the original information and this could affect the way they respond to inference questions.

Another study on belief perseverance by Golding and Hauselt (1994) may be more applicable for the current proposal. In this study the researchers recruited participants to participate in a creativity assessment. The researchers had confederates provide negative information to some of the participants about a teaching assistant involved in the study. Later the participants were asked to rate the teaching assistant on a scale of 1 (least nice) to 10 (nicest). One group of participants, the control group, did not hear any negative information about the teaching assistant. Group 2 heard the negative information; Group 3 heard the negative information but was instructed by the confederate to disregard it because "I probably should not have told you those things". And Group 4 heard the negative information but was instructed by the confederate to disregard it because "that wasn't the teaching assistant, it was someone else I was thinking about." The results showed that the negative information that the participants were exposed to continued to influence their evaluation of the teaching assistant, even when they were told to disregard it. However, the participants were more likely to disregard the negative information when the confederate asked the participants to forget the information because it was incorrect compared to when they were told to forget it because it should not have been revealed. Participants in both conditions rated the teaching assistant lower than the participants in the control condition. So, even though 
participants have reason to ignore the negative information it may be difficult to do so because of the associations and inferences that were formed after hearing the initial information.

The fact that jurors tend to consider inadmissible testimony demonstrates that jurors may be unable or unwilling to forget their initial inferences surrounding the inadmissible information. However, the jury's ability to disregard information may depend on a number of factors, such as the instruction to disregard information. Consider the following examples. In one study participants were asked to listen to a tape recording of a hypothetical trial in which the plaintiff had been injured when the car in which she was a passenger collided with a car driven by the defendant (Broeder, 1959). The participants were divided into three groups of juries; each group reviewed the same trial materials except for variations in a discussion of the defendant's insurance coverage. The first group learned that the defendant had no insurance, a fact admitted into evidence without objection. The participants awarded the plaintiff an average of $\$ 33,000$. The second group learned that the defendant had insurance, a fact also admitted into evidence without objection. The group two participants awarded the plaintiff an average of $\$ 37,000$. The third group learned that the defendant had insurance, but they also heard an objection to that evidence, and were instructed by the judge to disregard it. The third group of juries awarded the plaintiff an average of $\$ 46,000$. In this study it seems that an instruction to disregard information may cause jurors to give the evidence more weight than they would have otherwise. The authors concluded that the "fuss" made over the 
defendant's insurance simply emphasized that fact to the jury. So, the jurors in this study were not able to disregard the critical information.

However, there are particular instances in which the jury is more likely to be able to hear information and disregard it when told to do so. For example, jurors appear to be able to disregard information if the reason given is compelling. In one study, the participants read a summary of a criminal case in which the defendant was charged with murdering his estranged wife and a male neighbor (Kassin \& Sommers, 1997). The researchers divided the participants into four groups. The only difference across the four groups was whether incriminating statements made by the defendant during a tape recorded telephone call to a friend were presented, and if so, how the judge reacted to the incriminating statements. The phone call was not presented to the first group, and $24 \%$ of the participants in that group found the defendant guilty. The phone call was presented to the second group, and was ruled admissible over the defendant's objection. In the second group $79 \%$ of the participants found the defendant guilty. The phone call was also presented to the third and fourth groups, both of which were instructed to disregard it, for different reasons. The third group was told that the phone call evidence should be disregarded because it had been illegally obtained without a warrant, and 55\% of the participants in the third group found the defendant guilty. The fourth group was told that the phone call evidence should be disregarded because the audio tape was so inaudible that it could not be determined what was said. In this case only $24 \%$ of the participants found the defendant guilty. In this study those participants who were told to disregard the information because it was unreliable were able to disregard the 
information, compared to those participants who were told to disregard the information because it was obtained illegally. So, this study suggests that if the reason for exclusion is compelling, an instruction to disregard information allows the participant to act almost as if they had never been exposed to the information.

The findings just described suggest that if a compelling reason is given for the correction, then people are more inclined to alter their initial beliefs. In another study using mock jurors, the authors proposed that giving jurors instructions or information that elicit suspicion of ulterior motives might allow them to be less influenced by nonevidentiary information to which they have been exposed (Fein, McCloskey, \& Tomlinson, 1997). Suspicion not only provides compelling reasons to discredit the information completely but it also facilitates effective discounting (Fein, 1996; Fein, Hilton, \& Miller, 1990). An important manipulation used in the study is that the participants were made suspicious only after they read the information they were supposed to disregard. Previous studies of suspicion and discounting suggest that the effects of suspicion should be stronger if it precedes the information to be discounted (Fein, Hilton, \& Miller, 1990; Schul, 1993), so these studies provide a strong test of the power of suspicion. To arouse suspicion about incriminating information released in the press, the researchers exposed some participants to a newspaper article in which the defendant's attorney complained about the negative publicity and called into question the motives of the press for printing the incriminating information about his client. The results showed that the verdict (guilty or not guilty) of the participants in the suspicion condition resembled those of the participants who had not been exposed to the 
incriminating, non-evidentiary information. The participants who were exposed to the information but not given reason to be suspicious were more likely to convict the defendant, whether or not they were supposed to disregard the information. This is a very important finding for the current study because if participants are given reason to be suspicious of the information for example, if it comes from a low credibility source then they may be less likely to use the correction and continue using the original information when making inferences compared to participants whose correction comes from a more credible source. Suspicion of ulterior motives appears to be an effective way to help people disregard information they are instructed to forget.

I propose that a correction that comes from a highly credible source may serve the same function, to cause people to believe the correction and to question the reason for the original information. This process may ultimately allow people to discount the original information.

After reviewing multiple studies on juries' ability or inability to disregard information, Wistrich, Guthrie, and Rachlinski (2005) presented a few safe generalizations. First, when people attempt to ignore inadmissible information when making decisions or arriving at judgments about other people, they frequently will be unsuccessful. Second, such attempts are more likely to be successful if a) the inadmissible information is not needed to arrive at a sound decision; b) the inadmissible information is not highly salient or emotionally charged; c) the decision maker is not simultaneously subjected to heavy extraneous cognitive load; d) the credibility of the 
inadmissible information sought to be ignored is destroyed or at least called into question.

\subsection{Medical Decision Making}

As previously mentioned in the vaccines and autism example, the lingering effects of false inferences can have a huge impact on medical decision making. In this example, the media falsely reported a story which claimed that there is a link between the MMR vaccine and autism. The story was based on an initial study that subsequent research failed to support (Baron-Cohen, 2009). A correction was later posted, but for the parents of children with autism the story provided an explanation for why their child developed the condition. Even after the truth came out some parents chose to ignore it and instead they saw the researchers who reported the correction as part of a conspiracy to hide the truth. Similarly, according to webmd.com, during the swine flu (H1N1 virus) outbreak in 2009, Canadian scientists unpublished reports suggested that the H1N1 vaccine was harmful. Once the media picked up these reports people started believing that the vaccine did more harm than good. Even after the Food and Drug Administration (FDA) announced that the vaccine was not harmful people were still hesitant to get the vaccine. In fact, a national poll found that only $40 \%$ of American parents planned to vaccinate their children. This was surprising because the virus affected mostly children and young adults. So this rumor potentially had very harmful effects, when in actuality the odds that the vaccine would cause more harm than the virus were practically zero. Even more recently, the oral contraceptive Yasmin has been under fire. In April 2010, the FDA requested that new warning labels be placed on the product that warn that the 
risk of thromboembolic disorders is greater in Yasmin compared to other oral contraceptives. The makers of Yasmin, Bayer Health Care Pharmaceuticals, later commented that the risk is comparable to other oral contraceptives. So, in this situation the less credible source, the pharmaceutical company, corrected the statement made by the FDA. As it turns out, despite the correction from the pharmaceutical company, Yasmin sales dropped about 10.2\% by May 2010 (http://www.aboutlawsuits.com).

In another example, in September 2006 the FDA announced that an unknown source of fresh spinach had been contaminated with e.coli and advised against eating it until further notice. In total 200 people across 26 states got ill from eating the contaminated spinach. In a phone survey conducted a few months after the recall ended, researchers learned that $48 \%$ of the respondents ate spinach before the recall, and out of that $48 \%, 44 \%$ were eating spinach again within 2 weeks after the recall ended.

However, $5 \%$ of the respondents reported that they would never eat spinach again because of a fear, or possible lingering suspicion, that the spinach was not yet safe to eat. Interestingly, their data showed that many people stopped buying other similar fresh produce as well. This shows that inferences about the contaminated spinach transferred to similar produce even though there was never any e.coli found in any other fresh produce. This finding is very similar to the mad cow disease outbreak in March of 2005. According to the Congressional Research Service (CRS) report for congress, after a discovery of bovine spongiform encephalopathy (BSE or mad cow disease) prompted a beef recall, beef sales declined significantly even after the recall was lifted. A similar chain of events occurred when Tylenol capsules were recalled in 1982, however sales 
returned to normal after one year. These examples demonstrate how hesitant people can be to alter their beliefs after hearing negative information even if it is later corrected or is no longer applicable. This phenomenon has also affected vehicle sales. In January 2010, automobile manufacturer Toyota announced a recall on eight of their popular models due to faulty gas pedals. According to NPR (http://www.npr.org) after the recall was lifted, Toyota sales dropped $16 \%$, even on vehicles that were not affected by the recall. Some of Toyota's most faithful customers started purchasing Ford, General Motors, and Nissan vehicles, as can be seen by their increase in sales following the Toyota recall.

There are other everyday examples of this effect all around us. In my own experience, after enduring a catastrophic hurricane in southeast Texas my community was told not to drink the tap water as it may be contaminated. Even after the Red Cross informed us it was safe to drink the tap water again the local residents were hesitant because we could not be sure that it was safe to do so again, and many of us continued drinking bottled water after this announcement.

Similarly, when the AIDS virus was first reported by the Center for Disease Control (CDC) in 1981 people were confused about where it came from and how it was transmitted (Gallo, 2006). The fact that HIV/AIDS was a relatively new disease contributed to the stigma attached to it. The fear surrounding the emerging epidemic in the 1980s is still fresh in many people's minds. At that time very little was known about the risk of transmission, which made people scared of those infected due to fear of contagion (Herek \& Capitanio, 1993). Since the early 1980s we have learned a great deal about how the disease is transmitted and many of the initial false claims have been 
corrected. However, older adults who were very aware of the early stigma attached to AIDS may have more difficulty forgetting these assumptions. In fact, Herek (1999) cited several studies which found that younger and more highly educated people typically manifest lower levels of HIV related stigma than do older people and those who are less educated. This effect can also be seen when people are initially hesitant to take prescribed steroids or even medical marijuana because of the negative stigma or image portrayed in the media. These people are affected by their early interpretations of the drugs and have a hard time updating or correcting their mental models.

\subsection{Marketing}

Marketing research has examined the role of (product) commitment, or preferences, as a moderator of these negative information effects. Research in consumer behavior indicates that consumers become attached to various brands and form relationships with them (Fournier, 1998). The attitudes that consumers have for the brands are expected to vary in strength, this demonstrates their product commitment. Commitment has been shown to play a critical role in determining resistance to negative information (Ahluwalia, Burnkrant, \& Unnava, 2000). The authors of this study exposed high and low commitment consumers to positive and negative information about the product. They found that high commitment consumers chose to ignore the negative information and support the positive information, while low commitment consumers gave more weight to the negative information compared to the positive information. The authors attribute this finding to the negativity effect, which can often be seen in the impression formation literature (Fiske, 1980; Klein, 1996; Skowronski \& Carlston, 
1989). The negativity effect proposes that people place more weight on negative information compared to positive information because it is considered to be more diagnostic or informative than positive information (Maheswaran \& Meyers-Levy, 1990; Skowronski \& Carlston, 1989). In addition to this finding, research shows that it may be particularly difficult to forget negative or unpleasant information, and perhaps related inferences (Isbell, Smith, \& Wyer, 1998). Because of the high importance of the negative information, it may be particularly difficult to correct this type of information, be it about a political figure, a defendant, or a product. So, it seems that previous research in different domains provides evidence supporting the idea that credibility can influence the continued influence of incorrect inferences. However, there is also some evidence that credibility alone may not be able to diminish the effect. 


\section{SOURCE CREDIBILITY}

The extent of updating information can be dependent on the credibility of the new data (Chinn \& Brewer, 1993), or the credibility of the source of the new data. Previous research shows that the more people are presented with information, the more they believe it (e.g. Zajonc, 2001) and the more people are presented with something the more they attribute it to a credible source. For example, Fragale and Heath (2004) found that participants who were exposed to a statement many times were more likely to attribute it to Consumer Reports than to the National Enquirer. In experiment two of the same study participants read an article about a murder investigation that contained credible and noncredible sources. When the participants believed a particular suspect to be guilty, they misattributed evidence incriminating that suspect to the high credibility source. The authors demonstrated that this phenomenon occurred because the participants assumed their beliefs were true and that true beliefs come from credible sources.

Researchers have also examined source credibility and persuasiveness. In one study the authors found that revealing a source as having low credibility after the message is read enhanced the persuasiveness of the message, as compared to revealing this information before the message is read (Greenberg \& Miller, 1966). This finding is important because it suggests that if people hear information that is corrected before they hear the source of the information they may come to believe it more easily than if they hear the source up front. A more recent study found that when people generate primarily 
positive thoughts in response to a message (because the message contains strong arguments) and then learn of the source, high source credibility leads to more favorable attitudes than does low source credibility. However, when people have primarily negative thoughts in response to a message (because it contains weak arguments) high source credibility leads to less favorable attitudes than does low source credibility (Petty, Brinol, \& Tormala, 2002). The authors attributed their findings to the self-validation hypothesis. This hypothesis contends that thoughts held with high confidence have a strong impact on attitudes, whereas thoughts held with low confidence do not. So, thought confidence can increase or decrease persuasion depending on what thoughts are obtained from the message (Petty, Brinol, \& Tormala, 2002).

Through the use of a post-test questionnaire, previous research has suggested that participants may continue to use the incorrect initial information instead of the correction, because they believe they would not have been told the information if it were not true or because they believe it for personal reasons (e.g. Seifert, 2002). The wishful thinking literature addresses this very topic. Wishful thinking is a bias to attribute desirable predictions to a reliable source and undesirable predictions to an unreliable source. In a test of this, one study found that wishful thinking indeed affects source monitoring. So, source accuracy increased when the desirable outcome was predicted by a reliable source and when an undesirable outcome was predicted by an unreliable source. Likewise, source accuracy decreased when the desirable outcome was predicted by an unreliable source and when the undesirable outcome was predicted by a reliable source (Gordon, Franklin, \& Beck, 2005). This finding has important implications for 
the current study because people may tend to believe the desirable outcome and attribute it to the high credible source because of a wishful thinking bias.

The present study will modify the method used in the original Wilkes and Leatherbarrow (1988) study to examine whether manipulating the credibility of the source of the correction statement will allow participants to overcome the continued influence of inferences in memory. Given the preliminary finding that some participants may not even believe the correction because they think that it is just a cover up, the current study predicts that making the source of the correction more credible will cause people to believe it and thus use the correction when making inferences, instead of relying on the original information. Likewise, the current study will also examine how a low credibility source for the correction will influence participants' use of the original information and correction. Previous research would predict that making the source of the correction less credible would cause participants to use the original information, instead of the correction, more than a high credibility source. According to the source credibility theory there are two main elements that comprise a sources credibility, expertise and trustworthiness (Gilbert, Fiske, \& Lindzey, 1998).

As mentioned, the persistence of erroneous inferences is an important issue that plagues many domains of life. This study examined how the different elements of credibility, trustworthiness and expertise, affect peoples' decisions in the political domain. Experiment 1 examined source credibility as a function of both expertise and trustworthiness, while Experiments 2 and 3 attempted to isolate the individual contributions of these two types of credibility on use of the original information. 


\section{RESEARCH DESIGN AND METHODS}

\subsection{Credibility Norming}

Prior to running the three experiments several norming studies were conducted using separate groups of participants to determine what participants consider to be high credibility and low credibility sources within the story context, for each of the two elements of credibility: trustworthiness and expertise. In the norming studies each participant was presented with a story about a politician running for reelection. Somewhere in the story the participants read information stating that the politician was seen taking bribe money. At the end of the story the participants read a statement indicating that this piece of information was corrected and shown to be untrue. They were given a list of 32 sources and asked to judge how trustworthy or expert the correction would be coming from each of the provided sources on a scale from 1-7. For experiment 1, I selected sources that normed high on both factors and low on both factors (see Table 1). For experiment 2, I used the sources that normed high and low on expertise but neutral on trustworthiness (Table 1). And for experiment 3, sources that normed high and low on trustworthiness but neutral on expertise were selected (see Table 1). 
Table 1

Norming means for the source of the correction statement

\section{Expertise Trustworthiness}

\section{Experiment 1}

$\underline{\text { Source }}$

Federal Judge (High)

4.60

3.82

Homeless Man (Low)

1.56

1.78

\section{Experiment 2}

$\underline{\text { Source }}$

Prosecutor (High)

5.13

3.87

Political Opponent (Low)

2.92

3.83

\section{Experiment 3}

Source

Political Opponent (High)

2.92

3.83

Politician's Wife (Low)

2.92

1.92

\subsection{Experiment 1 Method}

Participants. Ninety undergraduates (30 in each condition) from Texas A\&M University participated in the study. The participants received course credit for their participation. 
Design. The study used a between-subjects design with condition (high credibility, low credibility, and control: no correction) as the manipulated variable. The participants were randomly assigned to one of the three conditions. In all three conditions participants read a story that contained a series of messages about a politician running for reelection.

Materials. Three versions of the story were used (see Appendix A). Each version of the story contained a critical piece of information. In the fifth message of the story, participants read that the politician was seen taking bribe money. In all conditions (high credibility, low credibility, and control) this information came from an unnamed source. In the correction conditions, later in the story the participants read a statement correcting this information. The statement explained that the previous report was incorrect and the politician never received any bribe money. In the high credibility condition the correction came from a high credibility source who was rated during norming as being high on both expertise and trustworthiness (federal judge). And in the low credibility condition the correction information came from a low credibility source who was rated during norming as being low on expertise and trustworthiness (homeless man).

Participants were informed at the outset of the study session that they would be asked to recall the story. They were told:

For this study we are interested in how people understand and remember reports. In this experiment you will see a series of statements based on real information that we obtained from a news source about a real event. All of the messages that you read will relate to one event about a politician running for re-election. You are to go through 
them at your own pace, and then I will ask you to recall what you have read. Once you have turned to a new message please do not turn back and re-read any previous information.

Once participants finish reading the story they were told:

Now, I would like you to write down, as accurately as possible, everything you remember reading in the report.

Participants received a questionnaire immediately after the free recall test. In each condition, participants received the same 20-item questionnaire. Half of the questions were designed so that they can be answered by recalling the literal content (e.g. "When did the politician announce his campaign for reelection?"), whereas the other half of the questions required the use of an inference to answer them (e.g. "Is there any reason to believe that the politician will not be reelected?"). Participants were also given a final question directly asking about the correction (e.g. "What was the point of the message from ?"). The order of the test questions was randomized, except for the question concerning the point of the correction, which always came at the end.

After each question (factual or inference) participants made a Remember, Know, or Believe judgment. They received instructions about how to make these judgments before receiving the questionnaire (see Appendix B). After completing the questionnaire, participants were given additional questions to answer about the story. The first was a behavioral question asking participants to rate how likely they would be to vote for the politician, and why. The participants responded on a scale of $1-7$, where 1 is highly unlikely and 7 is highly likely. Then the participants were given the same post-test 
questionnaire that was included in the Guillory and Geraci (2010) study. This questionnaire asked participants to indicate why they believed that there was a correction in the story. In the previous Guillory and Geraci study, results from this questionnaire showed that some participants believed that the correction was given as a cover up for the truth. As a manipulation check, participants were also asked to indicate how credible they believed the source of the correction was given the context of the story. The participants were then given a series of additional tests and questionnaires at the end of the experiment. These tests included a vocabulary test that was used to determine individual differences in crystallized intelligence, and a general demographic questionnaire, which included a question asking participant the rate the degree to which they identified as a liberal or conservative on a 1-7 scale, with 1 being extremely conservative and 7 being extremely liberal. Previous research has shown that generally conservatives show more structured and persistent cognitive styles in relation to judgments and decision making, while liberals are more responsive to informational complexity, ambiguity, and novelty (Jost, Glaser, Kruglanski, \& Sulloway, 2003). Thus, it is possible that conservatives will be less likely to update their mental models using the corrected information as compared to liberals. Participants also took a working memory test at the end of the experiment because previous studies (Wilkes \& Leatherbarrow, 1988; Guillory \& Geraci, 2010) have suggested that participants with a higher working memory should be more likely to use the correction instead of the original information when answering inference questions. Also, previous research has shown that limitations in working memory capacity may influence a reader's 
representation of a text (Mannes, 1994). Limitations in working memory may force a reader to give priority to new information for further processing, and this will cause the suppressed information to have less influence. Participants also received a questionnaire designed to assess paranoid thoughts in college students (Fenigstein \& Vanable, 1992). The questionnaire contains 20 statements, and participants were ask to respond to each item on a 5 point scale, where 1 means not at all applicable to me and 5 means extremely applicable to me (see Appendix C). This questionnaire tests whether participants who show higher levels of paranoia will be more suspicious of the reason for the correction and less likely to use the correction (regardless of whether it comes from a high or low credibility source) relative to participants who show lower levels of paranoia. Finally, participants were given the Need for Cognition scale (see Appendix D). This is an 18item questionnaire using a 9-point scale, which has been used in many studies examining source credibility. Previous research has shown that people high in the need for cognition are more likely to form their attitudes by paying close attention to relevant arguments (i.e., via the central route to persuasion), whereas people low in the need for cognition are more likely to rely on peripheral cues, such as attractiveness or credibility (Cacioppo \& Petty, 1982). Thus, this scale was included to examine whether participants who are low in need for cognition will be more likely to use the credibility of the source of the correction when answering inference questions. 


\subsection{Experiment 2 Method}

Participants. Sixty undergraduates (30 in each condition) from Texas A\&M University participated in the study. The participants received course credit for their participation.

Design. The study used a between-subjects design with condition (high credibility and low credibility) as the manipulated variable. The participants were randomly assigned to one of the two conditions. In both conditions participants read a story that contained a series of messages about a politician running for reelection.

Materials. Two versions of the story were used (see Appendix A). As in Experiment 1, early in the story participants read that the politician was seen taking bribe money. In both conditions (high credibility and low credibility) this information came from an unnamed source. Later in the story the participants read a statement correcting this information. In the high credibility condition the correction came from a high credibility source based on expertise (prosecutor) (refer to norming data). And in the low credibility condition this information came from a low credibility source based on expertise (political opponent) (refer to norming data). The procedure for this experiment was identical to the procedure used in Experiment 1.

\subsection{Experiment 3 Method}

Participants. Sixty undergraduates (30 in each condition) from Texas A\&M University participated in the study. The participants received course credit for their participation. 
Design. The study used a between-subjects design with condition (high credibility and low credibility) as the manipulated variable. The participants were randomly assigned to one of the two conditions. In both conditions participants read a story that contained a series of messages about a politician running for reelection.

Materials. Two versions of the story were used (see Appendix A). Early in the story participants read that the politician was seen taking bribe money and in both conditions (high credibility and low credibility) this information came from an unnamed source. Later in the story the participants read a statement correcting this information. In the high credibility condition the correction came from a high credibility source based on trustworthiness (political opponent). Describe the high and low credibility conditions using the norming data. And in the low credibility condition this information came from a low credibility source based on trustworthiness (politician's wife). The procedure for Experiment 3 was identical to the procedures used in Experiments 1 and 2. 


\section{EXPERIMENT 1 RESULTS}

The alpha level was set at $p<.05$ for the following analyses. Effect size (partial

eta squared; $\eta^{2}$ ) and mean square error (MSE) are reported for each statistic.

\subsection{Recall and Questionnaire}

Free Recall. First, overall recall performance was examined. The free recall test was scored using "idea units". An idea unit was recorded as being recalled if the participant reproduced all or a substantial part of its content; otherwise it was scored as absent. Idea units were scored by two judges acting independently. Agreement levels for the analysis were high, averaging around $95 \%$ agreement. Results showed that overall recall performance did not differ across conditions (High Credibility, $M=.60, S D=.13$; Low Credibility, $M=.61, S D=.15$; Control, $M=.55, S D=.21)$, F $(1,88)<1$.

Next, we examined participants' recall of the original message and the correction, with source of the correction, for those participants in the correction conditions (see Figure 1). Recall that in the high credibility condition the original message stated that the politician was seen taking bribe money, and the correction from the federal judge stated that he never received any bribe money. Results showed that the majority of participants recalled both the original message and the correction with the source of the correction (recall of both messages w/ source was 70\% in the High Credibility condition and $80 \%$ in the Low Credibility condition). This difference in recall across conditions was not significant, $F(1,88)=1.65, M S E=.36, \eta_{\mathrm{p}}^{2}=.02$. There was no significant difference in the number of participants who recalled the original 
message and correction without the source of the correction across conditions $(27 \%$ in the High Credibility condition and $13 \%$ in the Low Credibility condition), $F(1,88)=$ $2.0, M S E=.12, \eta_{\mathrm{p}}^{2}=.03$. Less than $1 \%$ of participants in each condition recalled only the original message without the correction.

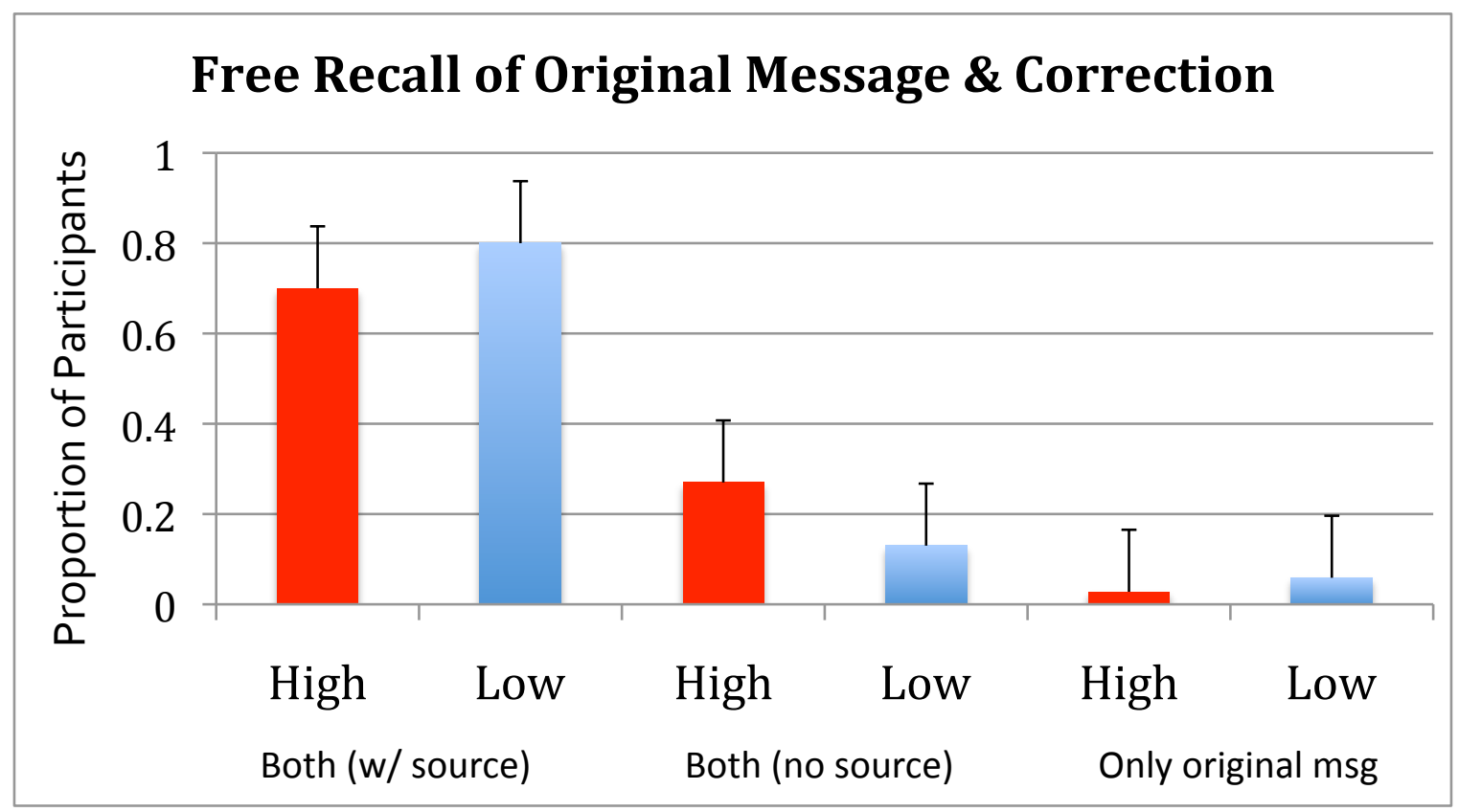

Figure 1. Exp 1: Free recall of original message and correction.

Questionnaire Responses. Next, we examined responses to the questionnaire. Half of the questions on the questionnaire were inference questions and the other half were factual questions. An example factual question asked, "When did the politician announce his campaign for re-election?". There were no significant differences in factual question recall across conditions (High Credibility $M=.76, S D=.17$; Low Credibility, $M=.77, S D=.19 ;$ Control $M=.70, S D=.19), \mathrm{F}(1,88)<1$. 
Next, we examined susceptibility to inferences across the three conditions. As an example, an inference question asked, "Are there reasons to believe that the politician will not be re-elected?". The answer to this question was not explicitly mentioned during the story, but participants could answer using inferences that they made based on the original message or the correction. Of interest was whether people answered inference questions using information from the original message. Responses to the inference questions were scored as using the original information (that is, the response is that the politician took a bribe) or some other response (including responses about bribe "rumors" or "alleged" bribery charges). Inference questions were only scored as using the original information if participants explicitly mentioned in their responses that the politician took bribe money. Following the questionnaire participants were asked to state what they thought was the purpose of the message from either the federal judge or homeless man (the source of the correction, depending on condition). Only participants who correctly recalled the purpose of the correction statement were included in the results. Thus, the results do not reflect differences in participants' ability to recall the critical message.

In the control condition participants never saw a correction message; they only received the original message regarding bribery. The use of the original information (bribe) to answer inference questions in this condition provides a baseline measure of use of the original information $(M=.29 ; S D=.19)$. In the correction conditions, results showed that in both the High Credibility condition $(M=.12 ; S D=.13)$ and the Low Credibility condition $(M=.23 ; S D=.17)$ receiving a correction decreased participants' 
reliance on original information in answering inference questions. Receiving a correction from a high credibility source significantly reduced participants' reliance on the original message compared to when the correction came from a low credibility source, $F(1,58)$ $=7.30, M S E=.02, \eta_{\mathrm{p}}^{2}=.11$, and compared to when there was no correction in the control condition, $F(1,58)=15.19, M S E=.03, \eta_{\mathrm{p}}^{2}=.21,$. Receiving a correction from a low credibility source did not significantly reduce participants' reliance on the original information above not receiving a correction at all, $F(1,58)=1.65, M S E=.03, \eta^{2} \mathrm{p}=$ .03. So, the results show that if a correction comes from a source who is high on both expertise and trustworthiness, compared to source who is low on both factors, participants were significantly less likely to use of the original information to answer inference questions.

Subjective Judgments. We also examined the subjective experience associated with answering factual and inference questions. For each response, participants were asked to indicate whether they remembered, knew or believed the information. As demonstrated in the Guillory and Geraci (2010) study, we hypothesized that inferences would be associated with believing, whereas factual questions would be associated with remembering. Figure 2 illustrates how often participants used each judgment to answer factual questions for the control and two correction conditions. There were no significant differences across conditions (high, low, and control) so the data is collapsed.

Participants in all three conditions gave more remember judgments than know or believe judgments to answer the factual questions (see Figure 2). A 3 × 3 ANOVA (for condition and subjective judgment) showed that there was no effect of condition (high, low, or 
control) $F(1,29)<1$. There was also no significant interaction between condition and subjective judgment $F(1,29)<1$. But there was a main effect of subjective judgment (remember, know, or believe) $F(1,29)=98.58, M S E=.06, \eta_{\mathrm{p}}^{2}=.77$, indicating that participants gave mostly remember judgments to the factual questions.

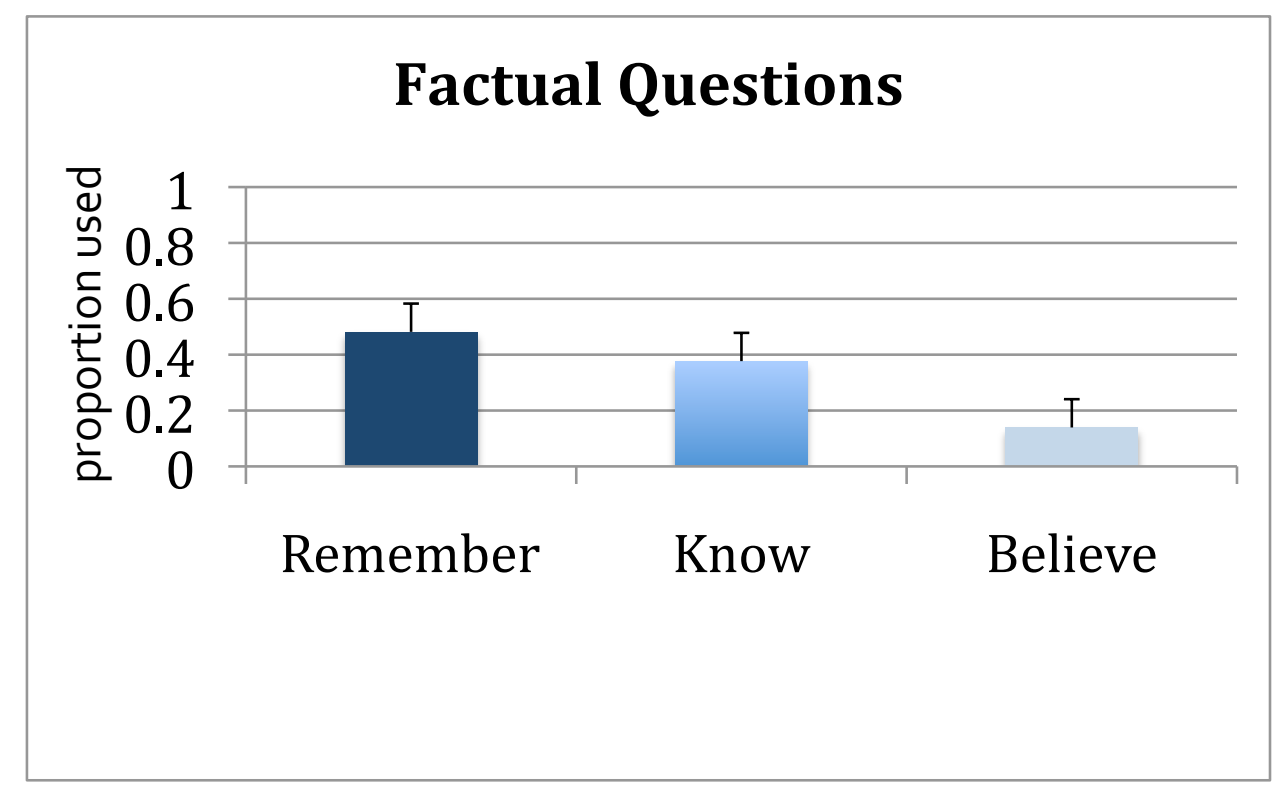

Figure 2. Exp 1: Remember/know/believe judgments for factual questions.

Consistent with the Guillory and Geraci (2010) study, the data also show that believe judgments were used more often than remember or know judgments when answering inference questions, in all three conditions $F(1,29)=582.80, M S E=.04, \eta^{2}$ p $=.95$. Condition $F(1,29)<1$, and the interaction between condition and subjective judgment were not significant $F(1,29)<1$ (see Figure 3). 


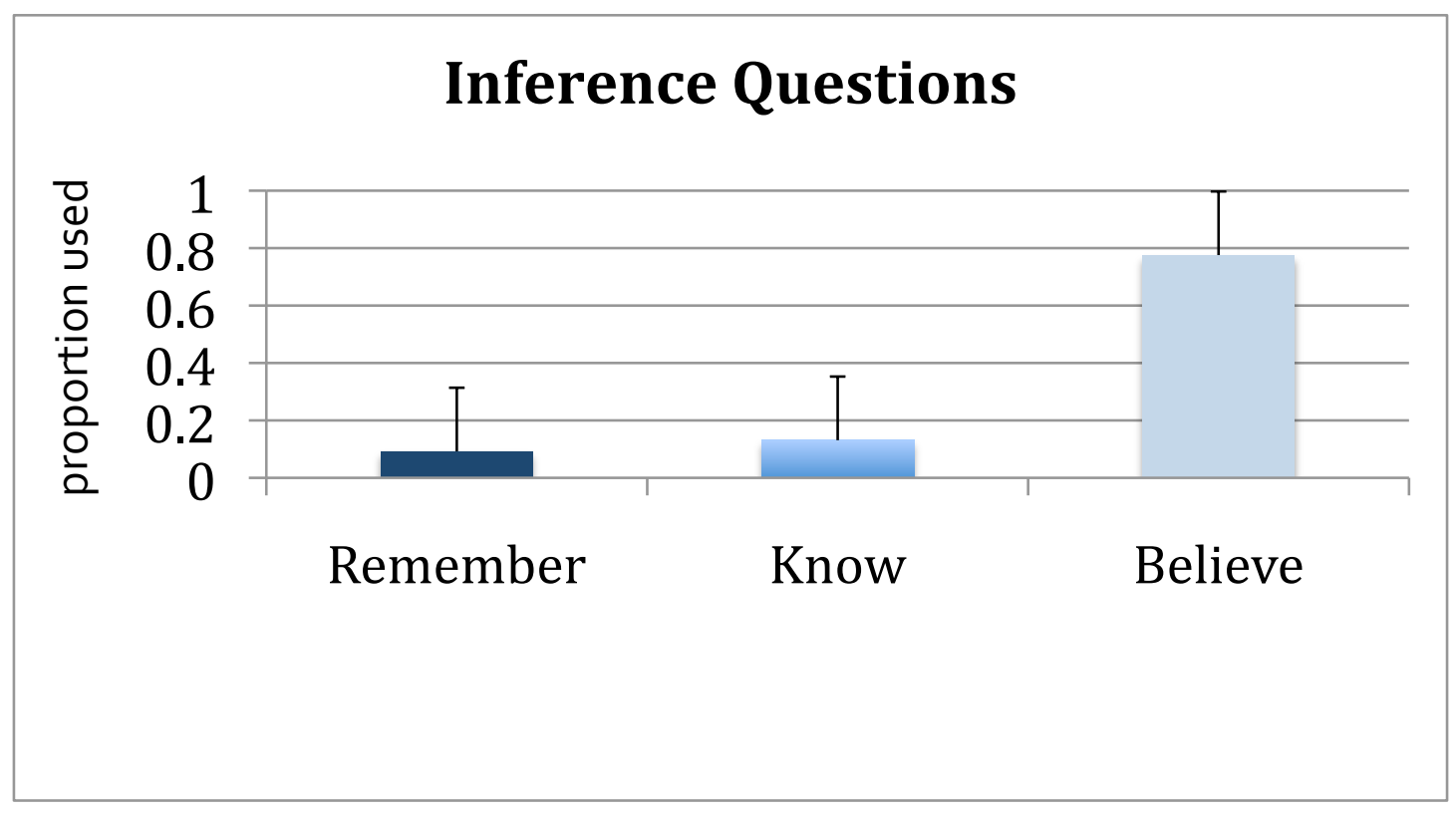

Figure 3. Exp 1: Remember/know/believe judgments for inference questions.

Participants were also asked to rate their confidence on a scale of 1-7 (with 1 being the lowest and 7 the highest) for each response following their remember, know, believe judgments (see Figures 4 and 5). There were no significant differences across conditions (high, low, and control) so the data is collapsed. The confidence data show that participants in all three conditions gave significantly lower confidence ratings for believe judgments relative to remember judgments $(t=10.34, d f=83, S E=.15, \mathrm{p}<.01)$. They also gave lower confidence ratings for responses that were given believe judgments relative to those that were given know judgments $(t=11.40, d f=83, S E=$ $.14, \mathrm{p}<.01)$. There was no significant difference in confidence rating between responses that were given remember judgments and those that were given know judgments $(t<1, d f$ $=83, S E=.14, \mathrm{p}=.73)$. We also examined confidence judgments by question type. The 


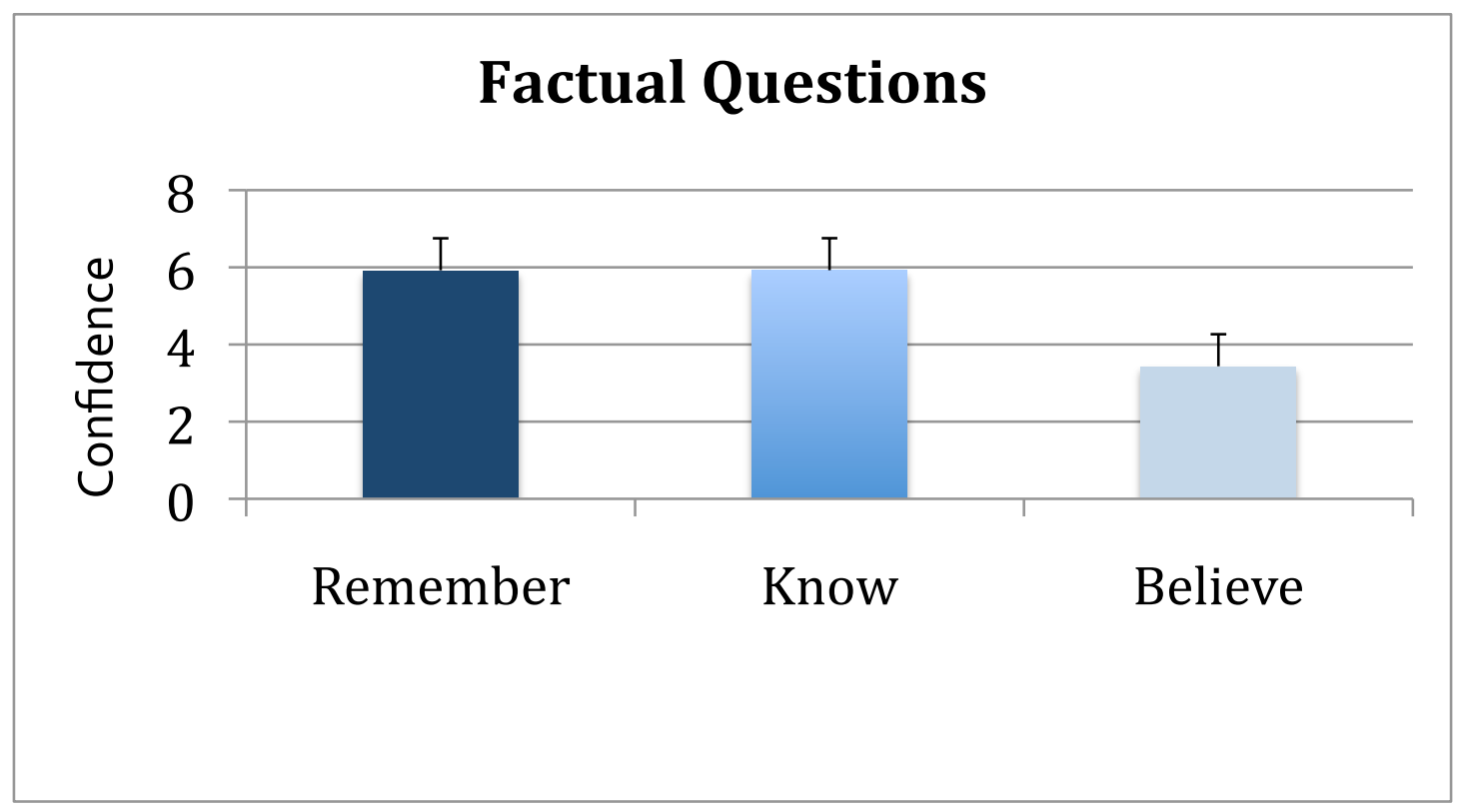

Figure 4. Exp 1: Confidence judgments for factual questions.

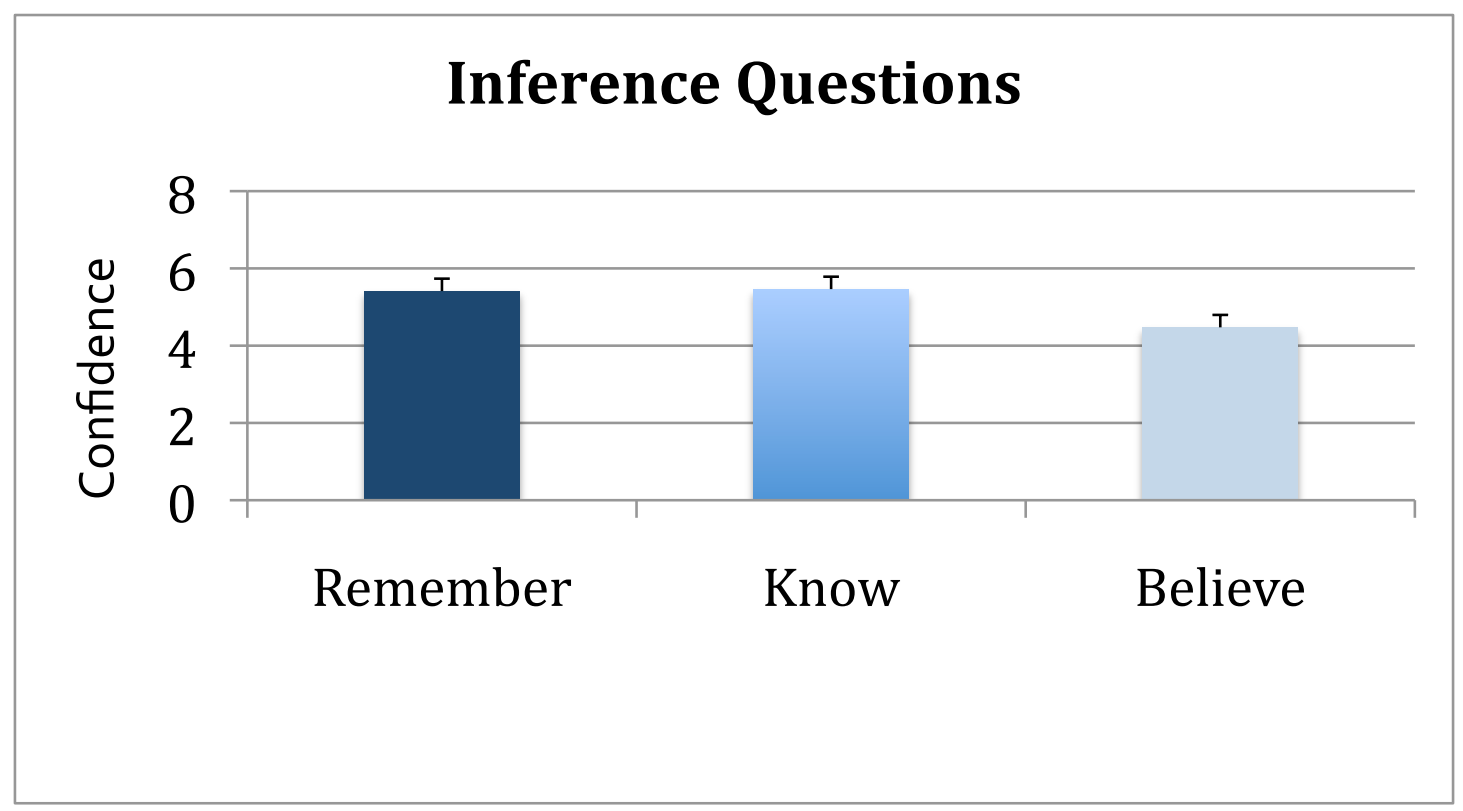

Figure 5. Exp 1: Confidence judgments for inference questions. 
results showed that participants gave significantly higher confidence ratings to answers of factual questions $(M=5.39 ; S D=1.54)$ in comparison to answers of inference questions $(M=5.01 ; S D=1.23)$ across conditions $(t=2.72, d f=175, S E=.14, \mathrm{p}<.01)$.

\subsection{Additional Tests}

Behavioral Measure Question. After completing the questionnaire, participants were asked to indicate how likely they would be to vote for the politician on a scale of 17, where 1 is the least likely and 7 is the most likely. In this experiment we did not find any differences in voting behavior across conditions (High: $M=4.43, S D=1.40$; Low: $M=4.38, S D=1.45$; Control: $M=4.20, S D=1.50), F(1,90)<1$, although the means were in the predicted direction. There were also no correlations between voting behavior and use of the original information across conditions, $r(88)=-.14, p=.21$.

Post-Test Questionnaire. Participants were given a post-test questionnaire that asked them to describe why they believed there was a correction in the story. The answers were categorized as one of three response types; 1) the person providing the correction lied, 2) the person providing the correction was simply correcting a mistake, and 3) some other reason for the correction that could not be placed into one of the previous two categories. The results indicated that participants in the low credibility correction condition were more likely to think that the correction occurred because the person providing the correction (the homeless man in low credibility condition) was lying. In contrast, participants in the high credibility correction condition were more likely to think the correction occurred because the person providing the correction (the 
federal judge in the high credibility condition) was simply correcting an earlier mistake (see Table 2).

Table 2

Exp 1: Reasons given for correction

Credibility Condition

High

Low

Response Type

Source of the correction lied

3

20

Source of the correction correcting a mistake

19

4

Other

7

6

If participants believed that the person providing the correction was lying, and that the original information was really true, then they may be more likely to continue using the original, incorrect information when answering inference questions about the story relative to people who believed that the correction was simply correcting a mistake. To test for this possibility, we examined the use of the original information (conditions collapsed) for participants who said the correction was a lie compared to those who said that the purpose of the correction was to correct a mistake. Participants who thought the correction was a lie were more likely to continue using the incorrect original information $(M=.25 ; S D=.17)$ than participants who thought the correction 
was simply correcting a mistake $(M=.12 ; S D=.12)$, and this difference was significant, $F(1,44)=8.65, M S E=.19, \eta_{\mathrm{p}}^{2}=.16$.

The second part of the post-test questionnaire asked participants, "On a scale of 1-7 (where 1 is the lowest and 7 is the highest) how credible and how trustworthy was the source of the correction?" This question provided a manipulation check, to verify that the high credibility source was seen as high credibility and the low credibility source was seen as low in credibility. Results showed that participants in the high condition ( $M$ $=4.60 ; S D=1.54)$ judged their source of the correction to be significantly higher in credibility than participants in the low credibility condition $(M=1.93 ; S D=1.11), F(1$, $58)=58.88, M S E=1.81, \eta_{\mathrm{p}}^{2}=.50$. Participants were also asked to rate the trustworthiness for the source of the correction statement (High: $M=4.30, S D=1.26$; Low: $M=2.13, S D=1.11)$. Results demonstrated that in the low credibility condition, low trustworthiness ratings were correlated with increased use of the original information on inference questions $r(28)=.45, p=.01$. Also, the results showed that in the low credibility condition low trustworthiness ratings were correlated with decreased voting behavior, $r(28)=.39, p=.04$. So if the participants in the low credibility condition judged the politician to be low in trustworthiness they were less likely to vote for him.

Working Memory Test Performance. There were no significant correlations between reading span scores and use of the original information in any condition or overall.

Paranoia Scale. After the initial tests, participants were given a series of additional tests to examine how specific factors influence use of the original information 
after it has been discredited. The first of these tests was a paranoia scale. Using a correlation we found an interesting pattern of results for participants in the high credibility and control conditions. For participants in the high credibility condition higher paranoia significantly correlated with decreased use of the original information, $r(28)=.39, p=.03$. In contrast, in the control condition, higher paranoia was correlated with increased use of the original information, $r(28)=.30, p=.11$, although this correlation did not reach significance (see Figure 6). This pattern of data is interesting because it shows that people who are highly paranoid and receive a high credibility correction about the politician not receiving bribe money are more likely to use the correction and believe that the original information must have been a lie. However, highly paranoid people in the control condition never saw the correction and yet they rely on the original information about the politician taking the bribe to answer inference questions more than participants with low levels of paranoia. 


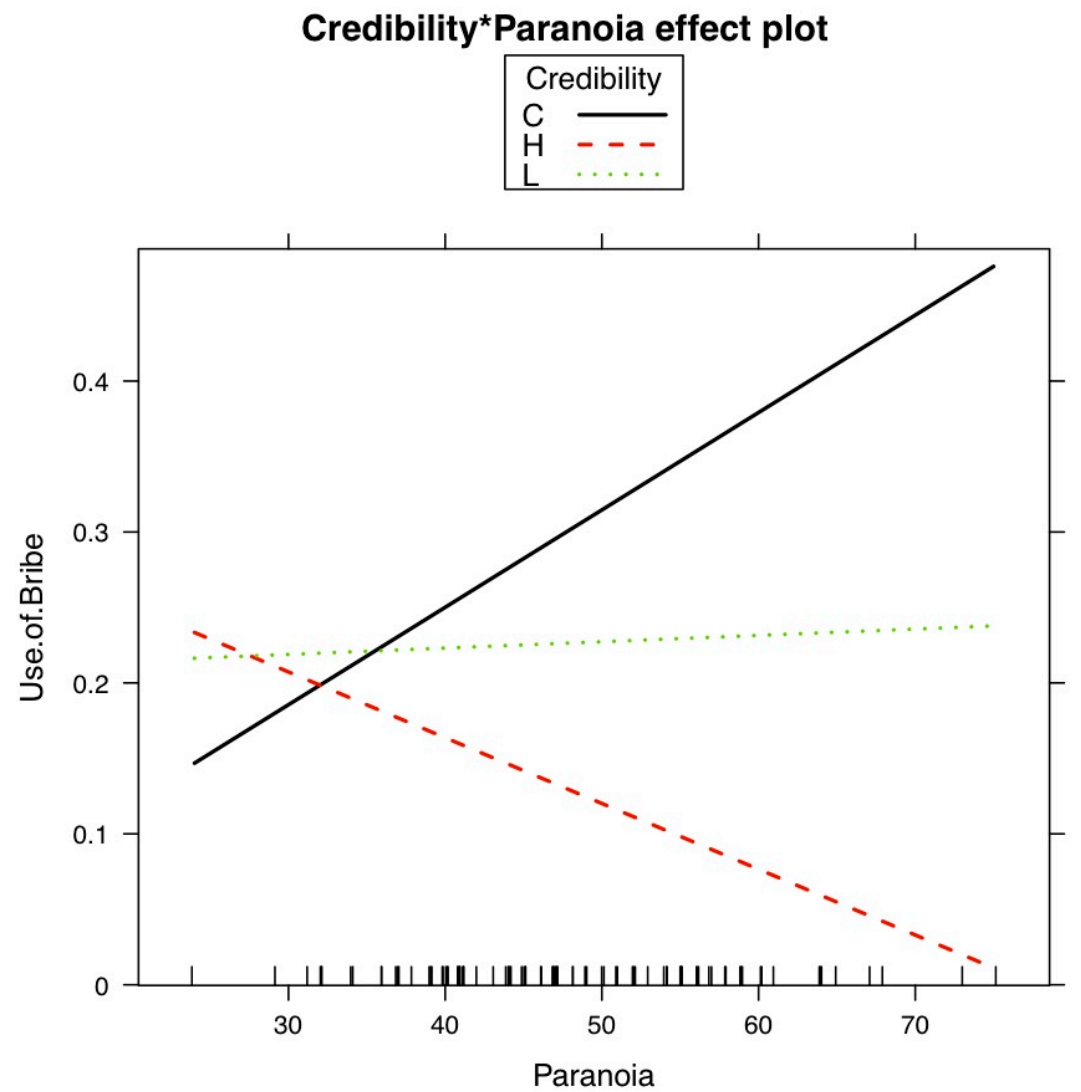

Figure 6. Exp 1: Participants use of original information by paranoia scores.

Need for Cognition Scale. Next, participants received a need for cognition questionnaire. While there were no significant differences in high and low need for cognition participants in the high credibility and control conditions, participants in the low credibility condition who scored high on the need for cognition scale were significantly more likely to continue using the original, discredited, information, $r(28)=$ $.42, p=.02$. This finding is consistent with past research demonstrating that people who are high in the need for cognition are more likely to form their attitudes by paying close attention to relevant arguments (i.e., via the central route to persuasion). If participants 
are high in the need for cognition and see a correction from a low credibility source (i.e., homeless man) then they may be more likely to disregard the correction and use the "relevant" information about the politician taking bribe money, in comparison to participants in the same condition who scored low on the need for cognition scale.

Vocabulary Test. Participants also received a vocabulary test. Results showed that higher vocabulary scores were correlated with an increased use of the original information $r(28)=.36, p=.05$ in the control condition. This finding suggests that when participants with higher vocabulary (crystallized intelligence) are never shown a correction they have better memory for the bribe message, and are more likely to use that information to answer inference questions compared to participants with lower vocabulary scores. There were no significant correlations in the high and low credibility conditions.

Political Affiliation. Finally, participants were asked to indicate whether they identify as a liberal or conservative on a 1-7 scale, with 1 being extremely conservative and 7 being extremely liberal. There were no significant correlations between political affiliation and use of the original message in any of the conditions (High: $r(28)=.26$, $p=.17$; Low: $r(28)=.22, p=.26$; Control: $r(28)=.14, p=.46)$.

So, in Experiment 1 where we manipulated credibility as a function of expertise and trustworthiness, we found that when the source of the correction statement is high in both factors it significantly decreases the use of the original information when answering inference questions. Experiments 2 and 3 will piece apart the individual contributions of expertise and trustworthiness. 


\section{EXPERIMENT 2 RESULTS}

Experiment 2 examines credibility as a function of expertise. The alpha level was set at $p<.05$ for the following analyses. Effect size $\left(\eta^{2}\right.$ p $)$ and mean square error $(M S E)$ are reported for each statistic.

\subsection{Recall and Questionnaire}

Free Recall. As in Experiment 1, in Experiment 2 the free recall test was scored by "idea units". An idea unit was recorded as being recalled if the participant reproduced all or a substantial part of its content; otherwise it was scored as absent. Idea units were scored by two judges acting independently. Agreement levels for the analysis were high, averaging around $95 \%$ agreement. Recall was not influenced by condition, (High, $M=$ $.66, S D=.12$; Low $, M=.65, S D=.14), F(1,58)<1$.

Next, we examined participants' recall of the original message and the correction, with the source of the correction. Recall that in the high credibility condition the original message stated that the politician was seen taking bribe money, and the correction from the prosecutor stated that the politician never received any bribe money. Results showed that many of the participants recalled both the original message and the correction with the source of the correction (High, 53\%; Low, 90\%). This difference in recall across conditions was significant, $F(1,58)=14.25, M S E=.16, \eta_{\mathrm{p}}^{2}=.20$. This difference in recall between the high and low conditions may be because in the high condition the prosecutor providing the correction is plausible in the story context so people didn't explicitly mention it during the free recall. However, all of the participants 
included in data analysis did recall the purpose of the message from the source of the correction (the final question on the questionnaire). For this reason, there was also a significant difference in the number of participants who recalled the original message and correction without the source of the correction across conditions ( $47 \%$ in the high condition and less than $1 \%$ in the low condition), $F(1,58)=14.91, M S E=.16, \eta_{\mathrm{p}}^{2}=.21$. Less than $1 \%$ of participants in each condition recalled only the original message without the correction (see Figure 7).



Figure 7. Exp 2: Free recall of original message and correction.

Questionnaire Responses. Next, we examined responses to the questionnaire. Half of the questions on the questionnaire were inference questions and the other half were factual questions. An example factual question asked, "When did the politician 
announce his campaign for re-election?". There were no significant differences in participants' ability to accurately answer the factual question recall across conditions (High, $M=.78, S D=.15$; Low, $M=.80, S D=.15)$, F $(1,58)<1$.

Next, we examined participants' susceptibility to inferences across the two conditions. As an example, an inference question asked, "Are there reasons to believe that the politician will not be re-elected?". The answer to this question was not explicitly mentioned during the story, but participants could answer it using inferences that they made based on the original message. Responses to the inference questions were scored as using the original information (that is, the response is that the politician took a bribe) or some other response (including responses about bribe "rumors" or "alleged" bribery charges). Inference questions were only scored as using the original information if participants explicitly mention that the politician took bribe money.

Results showed that in both the high credibility condition $(M=.19 ; S D=.16)$ and the low credibility condition $(M=.16 ; S D=.15)$ receiving a correction decreased participants' use of the original information in comparison relative to the control condition in Experiment 1. The difference between participants' use of the original information to answer inference questions in the high credibility condition and the low credibility condition was not significantly different $F(1,58)<1$. So, the results show that there was no significant decrease in participants' use of the original information if a correction came from a source that was simply more expert (but not more trustworthy) than another source. At the end of the questionnaire was a question that explicitly asked about the purpose of the message from the source of the correction statement (prosecutor 
or the politician's political opponent). Only participants who correctly recalled the purpose of the correction statement were included in the results.

Subjective Judgments. Next we examined the subjective experience associated with answering factual and inference questions. For each response, participants were asked to indicate whether they remembered, knew or believed the information. As demonstrated in the Guillory \& Geraci (2010) study, we hypothesized that inferences would be associated with believing, whereas factual questions would be associated with remembering. Figure 8 illustrates how often participants used each judgment to answer factual questions in the two correction conditions. There were no significant differences across conditions so the data is collapsed. Participants in both conditions gave more remember judgments than know or believe judgments to answer the factual questions (see Figure 8). A $2 \times 3$ ANOVA (for condition and subjective judgment) showed that there was no effect of condition (high or low) $F(1,29)<1$. There was also no significant interaction between condition and subjective judgment $F(1,29)=1.99, M S E=.09, \eta^{2}$ p $=.06$. But there was a main effect of subjective judgment (remember, know, or believe) $F(1,29)=40.05, M S E=.09, \eta_{\mathrm{p}}^{2}=.58$, indicating that participants gave mostly remember judgments to the factual questions. 




Figure 8. Exp 2: Remember/know/believe judgments for factual questions.

Consistent with the results from Guillory and Geraci (2010) study and those from Experiment 1 of this dissertation, the data show that believe judgments were used more often than remember or know judgments when answering inference questions, in both conditions $F(1,29)=209.23, M S E=.06, \eta_{\mathrm{p}}^{2}=.88$. Similar to factual questions, condition $F(1,29)<1$, and the interaction between condition and subjective judgment were not significant $F(1,29)<1$ (see Figure 9). 


\section{Inference Questions}

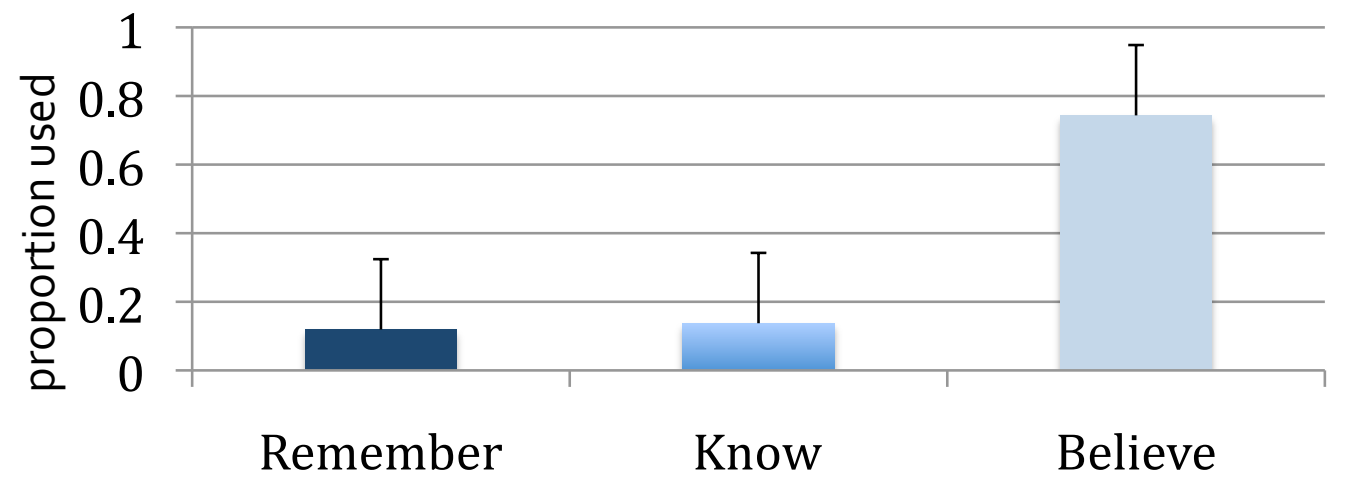

Figure 9. Exp 2: Remember/know/believe judgments for inference questions.

Participants were also asked to rate their confidence on a scale of 1-7 (with 1 being the lowest and 7 the highest) for each response following their remember, know, believe judgments (see Figures 10 and 11). There were no significant differences across conditions so the data is collapsed. The confidence data show that participants in both conditions gave significantly lower confidence ratings for believe judgments relative to remember judgments $(t=10.67, d f=50, S E=.16, \mathrm{p}<.01)$. They also gave lower confidence ratings for believe judgments relative to know judgments $(t=7.56, d f=51$, $S E=.19, \mathrm{p}<.01)$. There was no significant difference in confidence ratings between remember and know judgments $(t=1.46, d f=50, S E=.13, \mathrm{p}=.15)$. We also examined confidence ratings by question type. The results showed that participants gave higher confidence ratings to answers of factual questions $(M=5.67 ; S D=1.51)$ relative to answers of inference questions $(M=5.56 ; S D=1.08)$ across conditions $(t<1, d f=130$, 


\section{Factual Questions}

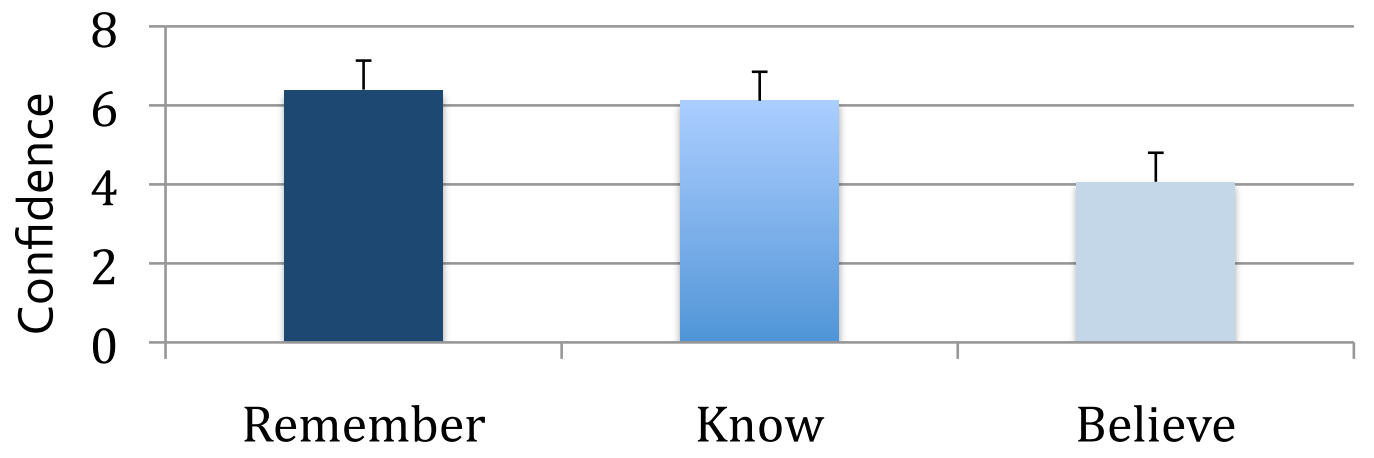

Figure 10. Exp 2: Confidence judgments for factual questions.

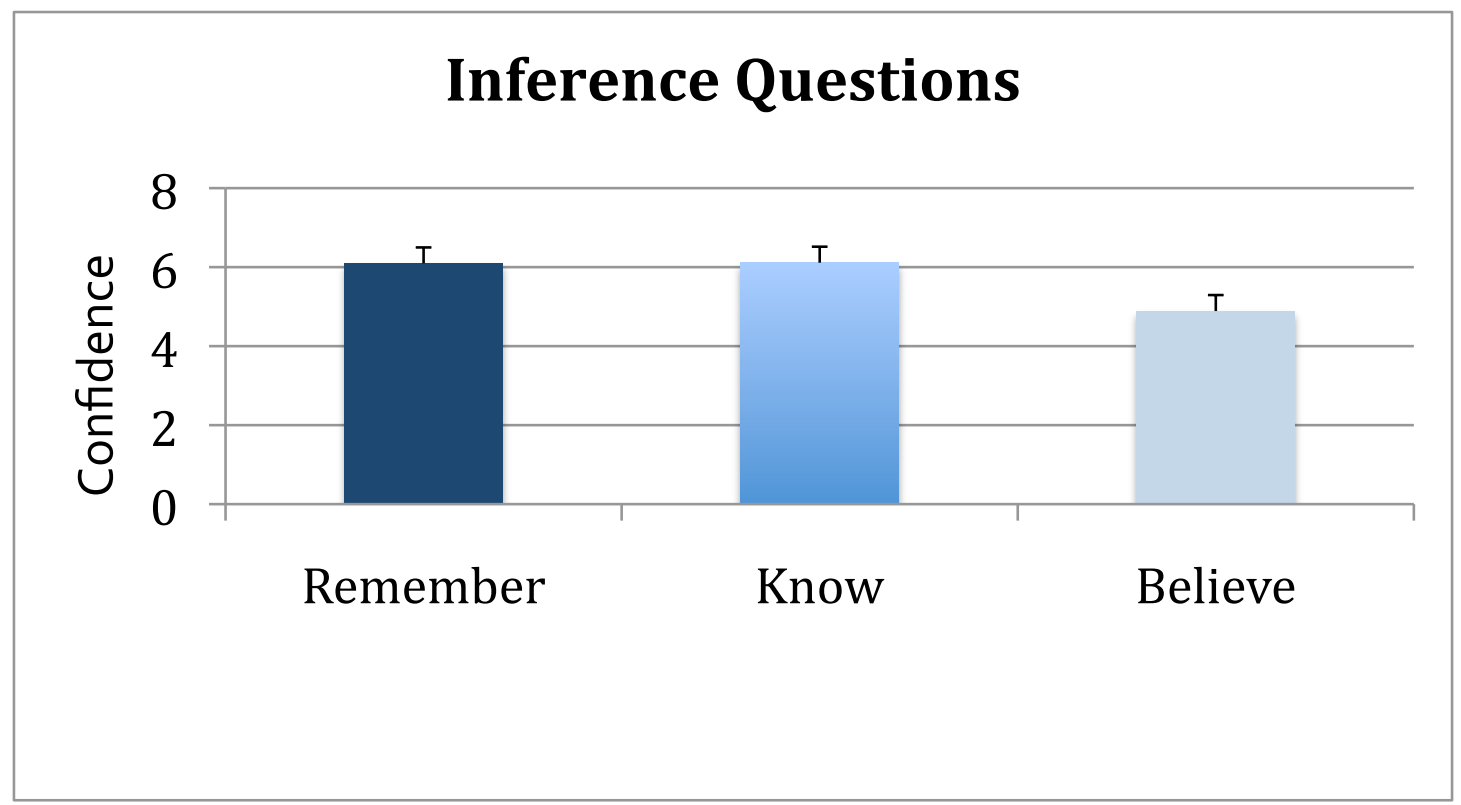

Figure 11. Exp 2: Confidence judgments for inference questions. 
$S E=.15, \mathrm{p}=.45)$ though this difference is not significant.

\subsection{Additional Tests}

Behavioral Measure Question. After completing the questionnaire, participants were asked to indicate how likely they would be to vote for the politician on a scale of 17, where 1 is the least likely and 7 is the most likely. Again, in this experiment we did not find any differences in voting behavior across conditions (High: $M=4.43, S D=$ 1.25; Low: $M=4.70, S D=1.18), F(1,58)<1$. There were also no correlations between voting behavior and use of the original information across conditions, $r(58)=.19, p=$ .14 .

Post-Test Questionnaire. Participants were given a post-test questionnaire that asked them to describe why they believed there was a correction in the story. The answers were separated into three responses; the person providing the correction lied, the person providing the correction was simply correcting a mistake, or if the participant gave some other reason for the correction that could not be placed into one of these two categories it was placed in an "other" category. The results indicated that most participants in both the high and low credibility conditions believed that the person providing the correction (prosecutor in the high condition and the political opponent in the low condition) was simply correcting an earlier mistake (see Table 3 ). This result may have occurred because, although participants judged the political opponent to be low in expertise and neutral in trustworthiness during norming, within the context of the entire experiment, the political opponent may have appeared more trustworthy. 
Table 3

Exp 2: Reasons given for correction

Credibility Condition

High Low

Response Type

Source of the correction lied

Source of the correction correcting a mistake

10

19

Other

13

5

Again, if participants believed that the person providing the correction was lying, and that the original information was really true, then they may be more likely to continue using the original, incorrect information, when answering inference questions about the story relative to people who believed that the correction was simply correcting a mistake $(n=13)$. To test for this possibility, we examined the use of the original information (conditions collapsed) for participants who said the correction was a lie compared to those who said it was correcting a mistake. Participants who thought the correction was a lie $(M=.24 ; S D=.19)$ were more likely to continue using the incorrect original information than participants who said the correction was correcting a mistake $(M=.10 ; S D=.10)$, this difference was significant, $F(1,24)=5.64, M S E=.02, \eta_{\mathrm{p}}^{2}=$ .19 . 
The second part of the post-test questionnaire asked participants, "On a scale of 1-7 (where 1 is the lowest and 7 is the highest) how credible was the source of the correction?" They were also asked to rate on a 1-7 scale the trustworthiness and expertise the source of the correction. These questions provided a manipulation check. Interestingly, counter to the norming results, participants in the high condition $(M=$ $3.80 ; S D=1.40)$ judged their source of the correction to be significantly lower in credibility than participants in the low credibility condition $(M=4.73 ; S D=1.41)$ when rating their source of the correction statement, $F(1,58)=6.61, M S E=1.98, \eta_{\mathrm{p}}^{2}=.10$. Also, the results showed that in the low credibility condition, high credibility ratings were correlated with increased voting behavior, $r(28)=.45, p=.01$. So if the participants in the low credibility condition judged the politician to be high in trustworthiness they were more likely to vote for him. Participants rated the source of the correction statement in the high $(M=3.53, S D=1.53)$ and low $(M=4.07, S D=1.46)$ credibility conditions as equally trustworthy, $F(1,58)=1.91, M S E=2.23, \eta_{\mathrm{p}}^{2}=.03$. Finally, participants rated the source of the correction statement in the high $(M=4.23, S D=$ 1.36) and low $(M=4.57, S D=1.07)$ credibility conditions as equally expert $F(1,58)=$ $1.12, M S E=1.50, \eta_{\mathrm{p}}^{2}=.02$. However, there were no significant differences in use of the original information on inference questions by participants post-test credibility ratings $(p=.83)$, so the data were collapsed.

We also examined credibility, expertise, and trustworthiness ratings by reason for the correction (see Table 4). 
Table 4

Exp 2: Credibility, expertise, \& trustworthiness ratings

Credibility Expertise Trustworthiness

\section{High}

$\underline{\text { Response Type }}$

Source of the correction lied 3.14

Source correcting a mistake

4.00

4.70

4.10

\section{Low}

Response Type

Source of the correction lied

Source correcting a mistake

Paranoia Scale. After the initial tests, participants were given a series of additional tests to examine how specific factors influence use of the original information after it has been discredited. The first of these tests was a paranoia scale, however we did not find any significant results in this experiment.

Need for Cognition Scale. Next, participants received a need for cognition questionnaire, however, need for cognition did not correlate with use of the original information in either condition. 
Vocabulary Test. Participants also received a vocabulary test, however vocabulary scores did not correlate with use of the original information in either condition.

Political Affiliation. Finally, participants were asked to indicate if they identify as a liberal or conservative on a 1-7 scale. There were no significant correlations between political affiliation and use of the original message (High: $r(28)=.07, p=.71$; Low: $r(28)$ $=.05, p=.80)$.

So, in Experiment 2 where we manipulated credibility as a function of expertise, we did not find any significant differences between the high and low conditions, suggesting that source expertise alone does not reduce the use of the original information when answering inference questions. 


\section{EXPERIMENT 3 RESULTS}

Experiment 3 examines credibility as a function of trustworthiness. The alpha level was set at $p<.05$ for the following analyses. Effect size $\left(\eta^{2} \mathrm{p}\right)$ and mean square error (MSE) are reported for each statistic.

\subsection{Recall and Questionnaire}

Free Recall. The free recall test was scored by “idea units". An idea unit was recorded as being recalled if the participant reproduced all or a substantial part of its content; otherwise it was scored as absent. Idea units were scored by two judges acting independently. Agreement levels for the analysis were high, averaging around 95\% agreement. Recall was not influenced by condition, (High, $M=.65, S D=.14$; Low, $M=$ $.61, S D=.15), F(1,58)=1.18, M S E=.58, \eta_{\mathrm{p}}^{2}=.02$.

Next, we looked at the participants' recall of the original message and the correction, with the source of the correction. For example, in the low credibility condition the original message stated that the politician was seen taking bribe money, and the correction from the politician's wife stated that he never received any bribe money. Results showed that most of the participants recalled both the original message and the correction with the source of the correction (High, 90\%; Low, 90\%); by contrast, less than $1 \%$ of the participants in each condition recalled the original message and correction without the source of the correction. And finally, less than $1 \%$ of participants in each condition recalled only the original message without the correction (see Figure 12). 


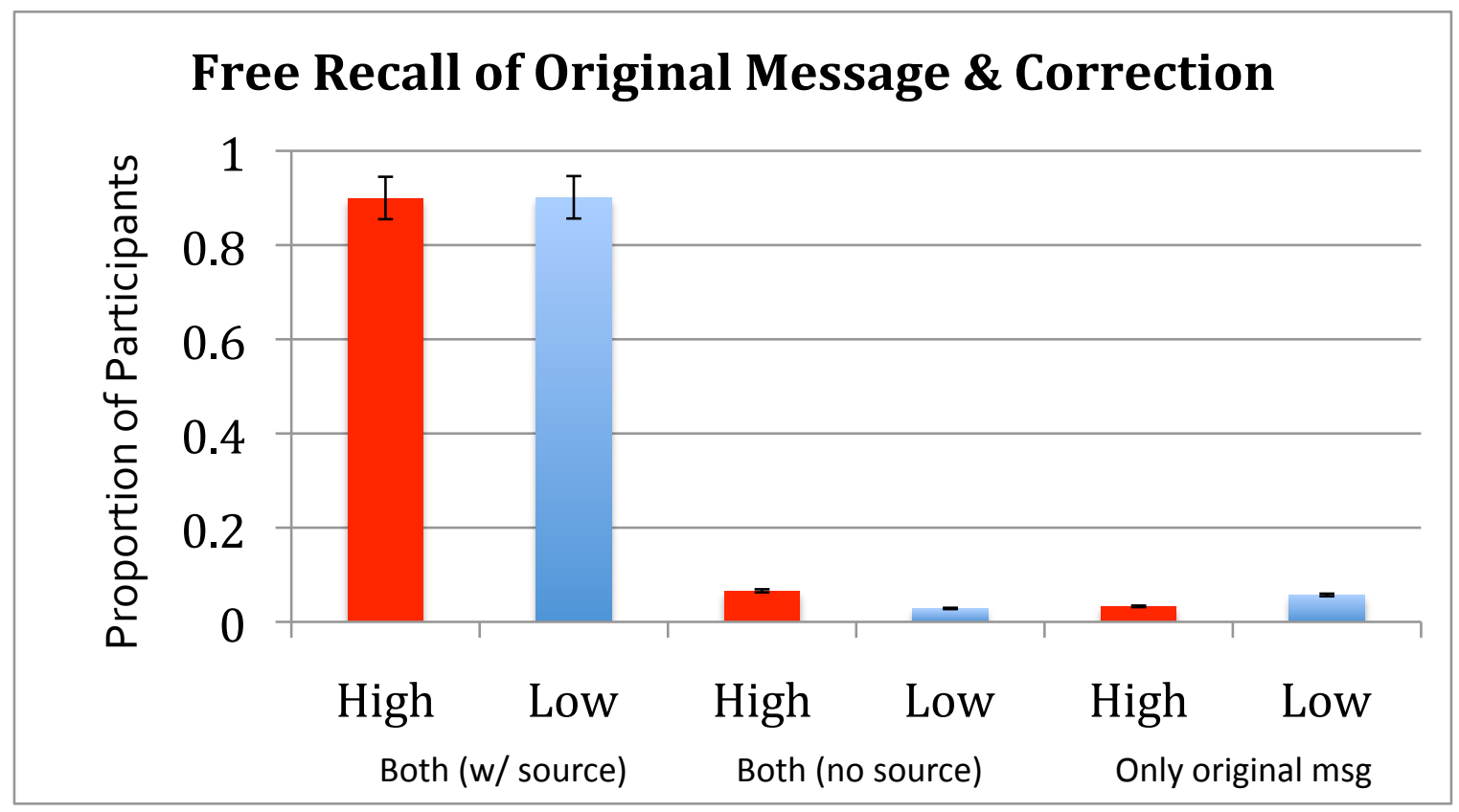

Figure 12. Exp 3: Free recall of original message and correction.

Questionnaire Responses. Next, we examined responses to the questionnaire. Half of the questions on the questionnaire were inference questions and the other half were factual questions. An example factual question asked, "When did the politician announce his campaign for re-election?". There were no significant differences in correct answers on factual questions across conditions (High, $M=.80, S D=.15$; Low, $M$ $=.74, S D=.19), \mathrm{F}(1,58)=1.61, M S E=.03, \eta_{\mathrm{p}}^{2}=.03$.

Next, we examined whether the source of the correction influenced participants' use of the original information when answering inference questions. As an example, an inference question asked, "Are there reasons to believe that the politician will not be reelected?". The answer to this question was not explicitly mentioned during the story, but participants could answer using inferences that they made based on the original message. 
Responses to the inference questions were scored as using the original information (that is, the response is that the politician took a bribe) or some other response (including responses about bribe "rumors" or "alleged" bribery charges). Inference questions were only scored as using the original information if participants explicitly mention that the politician took bribe money.

Results showed that in both the high credibility condition $(M=.16 ; S D=.15)$ and the low credibility condition $(M=.28 ; S D=.20)$ receiving a correction significantly decreased participants' use of the original information, $F(1,58)=6.99, M S E=.03, \eta_{\mathrm{p}}^{2}=$ .11. So, the results showed that participants were more likely to use the corrected information if that corrected information was provided by a trustworthy source, relative to an untrustworthy source. At the end of the questionnaire was a question which explicitly asked about the purpose of the message from the source of the correction statement (the politician's political opponent or the politician's wife). Only participants who correctly recalled the purpose of the correction statement were included in the results.

Subjective Judgments. We also examined the subjective experience associated with answering factual and inference questions. For each response, participants were asked to indicate whether they remembered, knew or believed the information. As demonstrated in the Guillory \& Geraci (2010) study, we hypothesized that inferences would be associated with believing, whereas factual questions would be associated with remembering. Figure 13 illustrates how often participants used each judgment to answer factual questions in the two correction conditions. There were no significant differences 
across conditions so the data is collapsed. Participants in both conditions gave more remember judgments than know or believe judgments to answer the factual questions (see Figure 13).

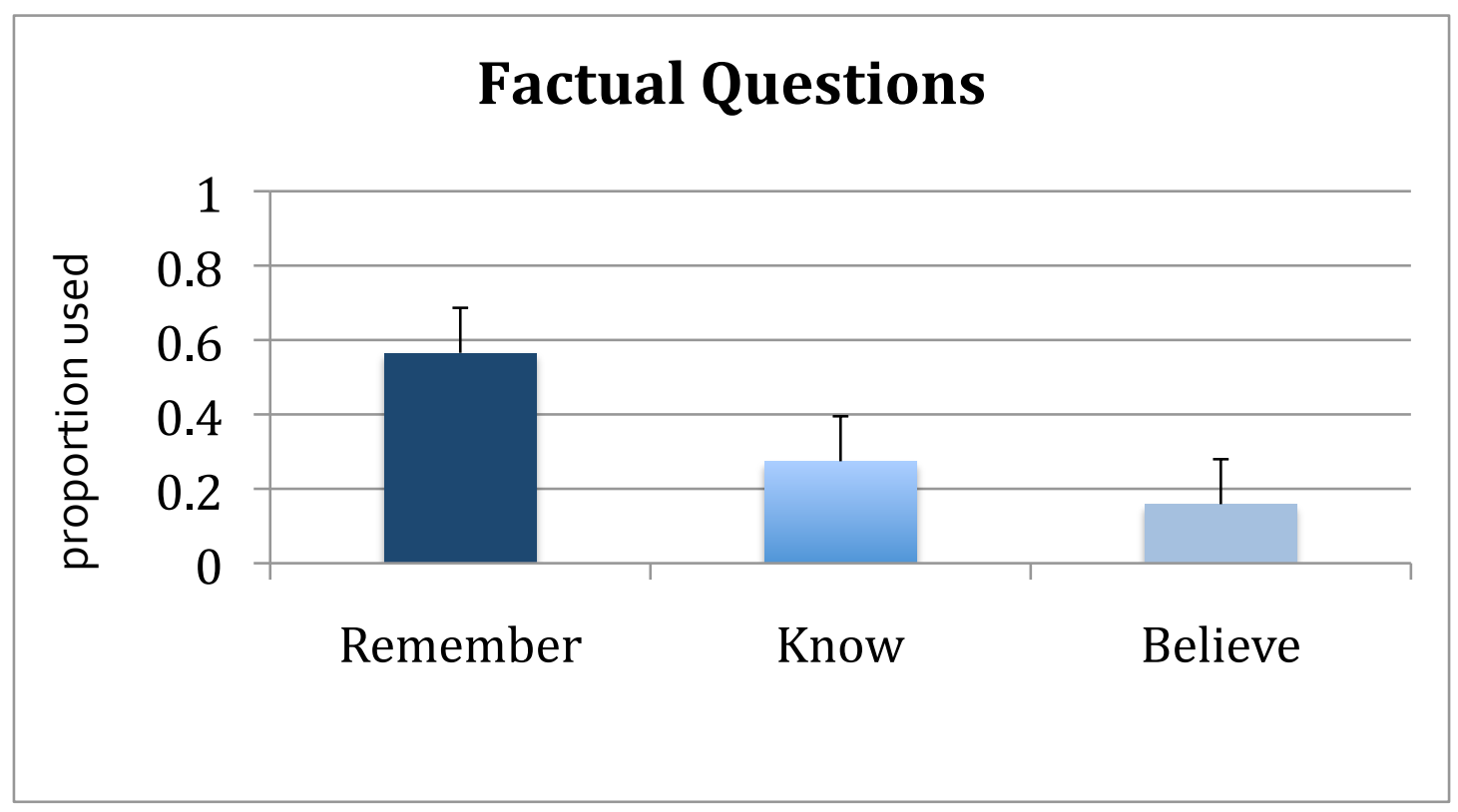

Figure 13. Exp 3: Remember/know/believe judgments for factual questions.

A $2 \times 3$ ANOVA (for condition and subjective judgment) showed that there was no effect of condition (high or low) $F(1,29)<1$. There was also no significant interaction between condition and subjective judgment $F(1,29)<1$. But there was a main effect of subjective judgment (remember, know, or believe) $F(1,29)=65.67, M S E$ $=.08, \eta_{\mathrm{p}}^{2}=.03$, indicating that participants gave mostly remember judgments to the factual questions. Interestingly, the data also show that believe judgments were used more often than remember or know judgments when answering inference questions, in 
both conditions $F(1,29)=388.07, M S E=.04, \eta_{\mathrm{p}}^{2}=.93$. Similar to factual questions, condition $F(1,29)<1$, and the interaction between condition and subjective judgment were not significant $F(1,29)=2.16, M S E=.03, \eta^{2} \mathrm{p}=.07$ (see Figure 14).

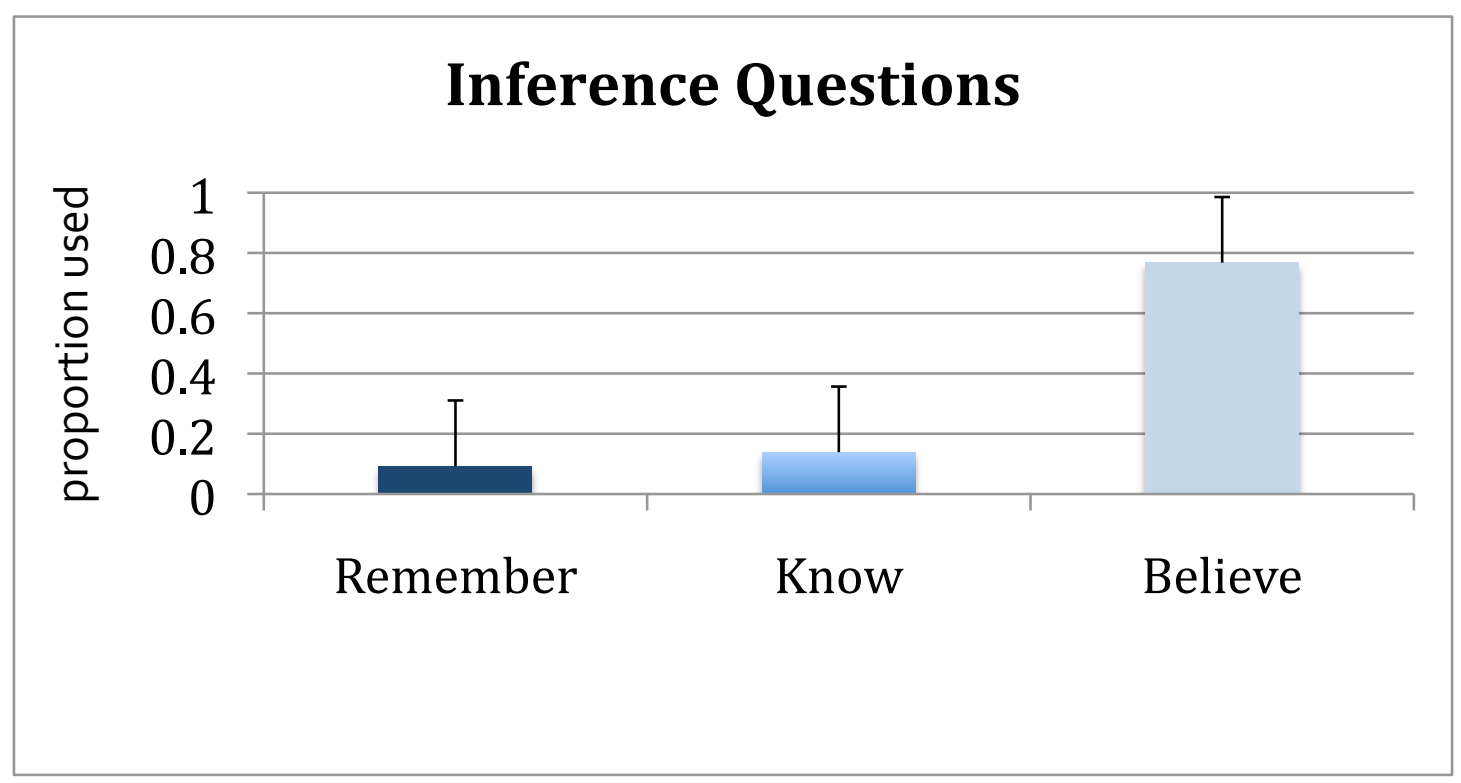

Figure 14. Exp 3: Remember/know/believe judgments for inference questions.

Participants were also asked to rate their confidence in their response using a scale of 1-7 (with 1 being the lowest and 7 the highest) for each response following their remember, know, believe judgments (see Figures 15 and 16). There were no significant differences across conditions so the data is collapsed. The confidence data show that participants in both conditions gave significantly lower confidence ratings for believe judgments relative to remember judgments $(t=7.59, d f=55, S E=.17, p<.01)$. They also gave lower confidence ratings for believe judgments relative to know judgments $(t=$ $5.99, d f=49, S E=.19, p<.01)$. There was no significant difference in confidence rating 


\section{Factual Questions}

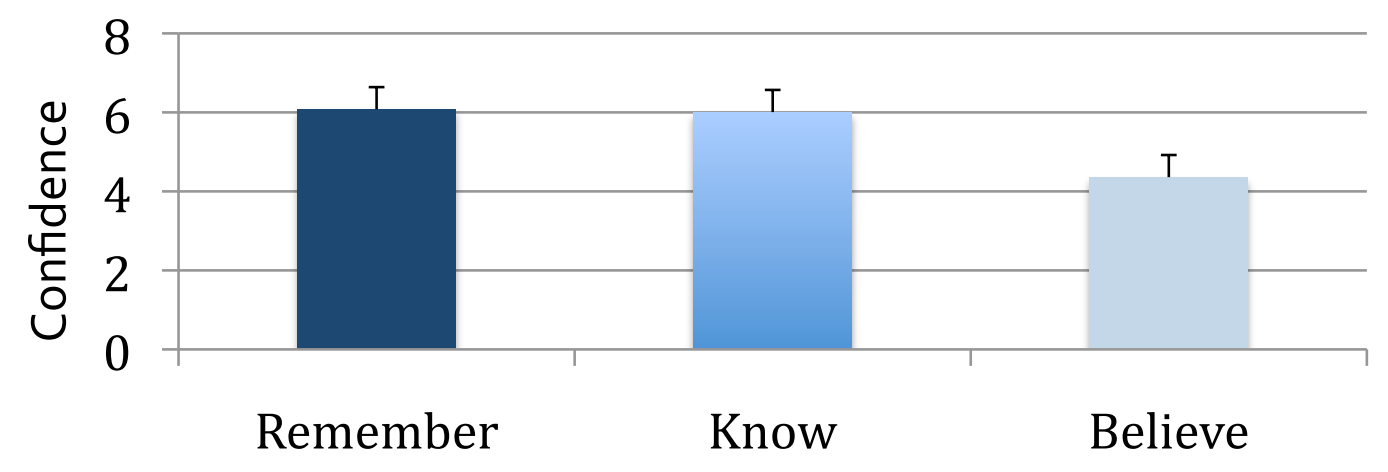

Figure 15. Exp 3: Confidence judgments for factual questions.

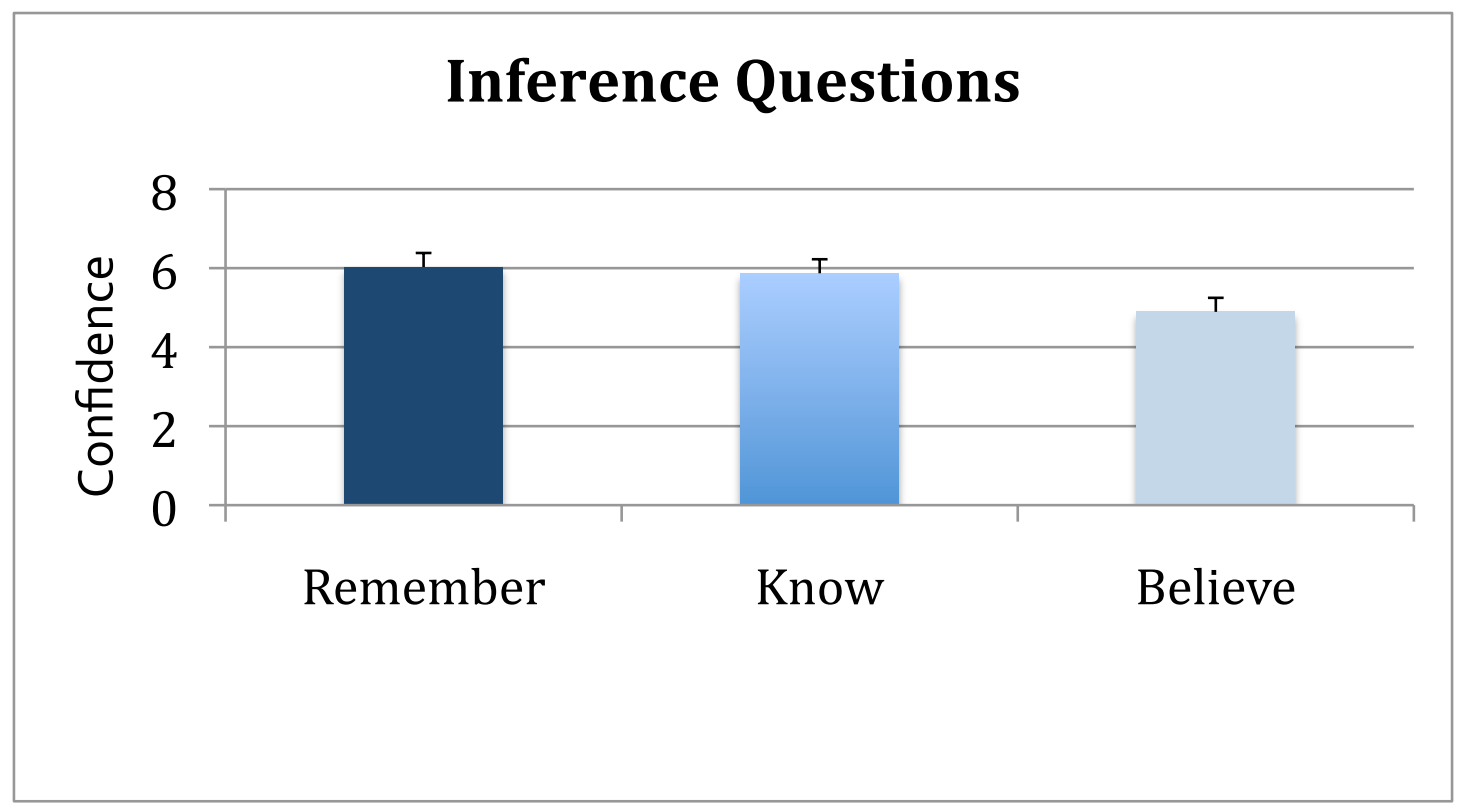

Figure 16. Exp 3: Confidence judgments for inference questions. 
between remember and know judgments $(t<1, d f=48, S E=.20, p=.63)$. We also examined confidence judgments by question type. The results showed that participants gave higher confidence ratings to factual questions $(M=5.53 ; S D=1.44)$ in comparison to inference questions $(M=5.44 ; S D=1.09)$ across conditions $(t<1, d f=$ $103, S E=.16, p=.60)$ though this difference is not significant.

\subsection{Additional Tests}

Behavioral Measure Question. After completing the questionnaire, participants were asked to indicate how likely they would be to vote for the politician on a scale of 17, where 1 is the least likely and 7 is the most likely. Again, in this experiment we did not find any differences in voting behavior across conditions (High: $M=4.70, S D=$ 1.18; Low: $M=4.30, S D=1.42), F(1,60)=1.41, M S E=1.70, \eta_{\mathrm{p}}^{2}=.02$. There were also no correlations between voting behavior and use of the original information across conditions, $r(58)=-.08, p=.56$.

Post-Test Questionnaire. Participants were given a post-test questionnaire that asked them to describe why they believed there was a correction in the story. The answers were separated into three responses; the person providing the correction lied, the person providing the correction was simply correcting a mistake, or if the participant gave some other reason for the correction that could not be placed into one of these two categories it was placed in an "other" category. The results indicate that most participants in both the high and low credibility conditions believed that the person providing the correction (the political opponent in the high condition and the politician's wife in the low condition) was simply correcting an earlier mistake (see Table 5). 
Table 5

Exp 3: Reasons given for correction

Condition

High Low

$\underline{\text { Response Type }}$

Source of the correction lied

$6 \quad 11$

$\begin{array}{lll}\text { Source of the correction correcting a mistake } & 19 & 10\end{array}$

$\begin{array}{lll}\text { Other } & 5 & 9\end{array}$

Again, if participants believed that the person providing the correction was lying, and that the original information was really true, then they may be more likely to continue using the original, incorrect information, when answering inference questions about the story relative to people who believed that the correction was simply correcting a mistake. To test for this possibility, we examined the use of the original information (conditions collapsed) for participants who said the correction was a lie compared to those who believed it was simply correcting a mistake. Participants who thought the correction was a lie $(M=.31 ; S D=.23)$ were more likely to continue using the incorrect original information than participants who said the correction was simply correcting a mistake $(M=.17 S D=.16)$, this difference was significant, $F(1,32)=3.93, M S E=.04$, $\eta_{\mathrm{p}}^{2}=.11$. 
As a manipulation check, the second part of the post-test questionnaire asked participants, "On a scale of 1-7 (where 1 is the lowest and 7 is the highest) how credible was the source of the correction?" They were also asked to rate on a 1-7 scale the trustworthiness and expertise the source of the correction. Results showed that participants in the high condition $(M=4.73 ; S D=1.41)$ judged their source of the correction to be significantly higher in credibility than participants in the low credibility condition $(M=2.93 ; S D=1.55), F(1,58)=22.07, M S E=2.20, \eta_{\mathrm{p}}^{2}=.28$. Participants were also asked to rate the trustworthiness of the source of the correction statement in the high $(M=4.07, S D=1.46)$ and low $(M=2.97, S D=1.73)$ credibility conditions, and this difference was significant, $F(1,58)=7.07, M S E=2.57, \eta_{\mathrm{p}}^{2}=.11$. Also, the results showed that in the low credibility condition high trustworthiness ratings were correlated with increased voting behavior, $r(28)=.45, p<.01$. So if the participants in the low credibility condition judged the politician to be high in trustworthiness they were more likely to vote for him. Finally, participants rated the expertise of the source of the correction statement in the high $(M=4.57, S D=1.07)$ and low $(M=3.03, S D=1.69)$ credibility conditions, this difference was also significant, $F(1,58)=17.58, M S E=$ $2.01, \eta_{\mathrm{p}}^{2}=.23$. We also examined credibility, expertise, and trustworthiness ratings by reason for the correction (see Table 6).

Paranoia Scale. After the initial tests, participants were given a series of additional tests to examine how specific factors influence participants' use of the original information after it has been discredited. The first of these tests was a paranoia scale, however we did not find any significant results in this experiment. 
Need for Cognition Scale. Need for cognition did not correlate with use of the original information in either condition.

Table 6

Exp 3: Credibility, expertise, \& trustworthiness ratings

Condition

\begin{tabular}{cc} 
Condition \\
\hline Credibility $\quad$ Expertise Trustworthiness
\end{tabular}

High

$\underline{\text { Response Type }}$

$\begin{array}{llll}\text { Source of the correction lied } & 3.50 & 4.50 & 2.83\end{array}$

$\begin{array}{lll}\text { Source of the correction correcting mistake } & 5.16 & 4.58\end{array}$

Low

$\underline{\text { Response Type }}$

$\begin{array}{llll}\text { Source of the correction lied } & 2.27 & 2.55 & 2.09\end{array}$

$\begin{array}{lll}\text { Source of the correction correcting mistake } & 3.40 & 3.60\end{array}$

Vocabulary Test. Participants also received a vocabulary test, however, vocabulary scores did not correlate with use of the original information in either condition.

Political Affiliation. Finally, participants were given a demographic questionnaire. In this questionnaire, participants were given a question asking if they identify as a liberal or conservative on a 1-7 scale. We did not find any significant 
correlations between political affiliation and use of the original message (High: $r(28)=$ $.05, p=.80 ;$ Low $r(28)=.11, p=.54)$. 


\section{SUMMARY}

The present study examined whether the source of a correction's credibility influences whether people use the correction, or if they continue to rely on the original incorrect information when making inferences. In Experiment 1, using a source that was high on both trustworthiness and expertise significantly decreased the use of the original information when answering inference questions. Experiment 2 demonstrated that holding trustworthiness neutral and manipulating only expertise does not decrease the use of the original information when answering inference questions. By contrast, Experiment 3 showed that when you hold expertise neutral and manipulate only trustworthiness you can get a significant decrease in the use of the original information when the source is high on trustworthiness, compared to when the source is low on trustworthiness. Thus, these data are the first to provide direct support for the hypothesis that making the source of a correction more believable decreases use of the original discredited information when making inferences.

Although the persistence of inferences in memory has been demonstrated in a number of studies (Wilkes \& Leatherbarrow 1988; Johnson \& Seifert 1994, 1999; Wilkes \& Reynolds, 1999; Guillory \& Geraci 2010), researchers have yet to explain why people continue to believe their erroneous inferences in the face of counter information. One assumption is that participants continue to use the original information because they believe that the correction is simply a cover up to the truth. In a recent study (Guillory \& Geraci, 2010), participants were asked to describe why they believed there was a 
correction in the story. The results showed that more than a third of the participants believed that the correction was a cover up for the truth, suggesting that they continued to believe the original information. In the present study we attempted to reduce the lingering memory effects of erroneous inferences by making the source of the correction more believable. To do this, we manipulated the credibility (expertise and trustworthiness) of the source of the correction.

In Experiment 1 we examined source credibility as a function of both expertise and trustworthiness. The results of this experiment showed that when the source of the correction statement was high on both expertise and trustworthiness it significantly decreased the use of the original information when answering inference questions. This is the first study that we know of which demonstrates that the credibility of the source of the correction statement influences whether people use the correction or continue to rely on the original information. This finding demonstrates the importance of considering the source of the correction statement. When the correction came from a source that was low on expertise and trustworthiness, use of the original information did not differ from the control condition where participants never even received a correction statement. This finding is relevant not only in politics, but can be useful in many different domains. If new information is to be used when making an inference, it should come from a source that is both expert and trustworthy.

Results from Experiment 1 also demonstrated that the majority of participants in the low credibility condition believed that the person providing the correction statement (homeless man) was lying, while the majority of participants in the high credibility 
condition believed that the person providing the correction (federal judge) was correcting an earlier lie or mistake. This was the first study to show that who issues the correction effects whether people will believe (and use) the correction, or if they will continue to rely on the original incorrect information.

This study was also the first to give participants a paranoia scale (Fenigstein \& Vanable, 1992). We hypothesized that participants who showed higher paranoia would be more suspicious and less likely to use the correction (whether it comes from a high or low credibility source). Interestingly we found that participants in the high credibility condition (source high on both expertise and trustworthiness) who scored high on the paranoia scale showed decreased use of the original incorrect information when answering inference questions. In contrast, participants in the control condition (who never saw a correction) who scored high on the paranoia scale showed increased use of the original incorrect information when answering inference questions. This means that when highly paranoid participants saw a correction from a high credibility source they were more likely to use the correction and believe that the original message was untrue for some reason, however when highly paranoid participants never received the correction message they relied on the original information even more than participants who showed lower levels of paranoia.

In Experiments 2 and 3 we aimed to piece apart the individual contributions of expertise and trustworthiness as factors of credibility. In Experiment 2 we held trustworthiness constant and manipulated source expertise. In this experiment we found that while receiving a correction does decrease use of the original information in 
comparison to the control condition (where participants did not receive a correction) there were no significant differences across high and low expertise corrections. Similarly, results showed that participants in both the high and low (expertise) conditions believed that the correction statement was simply correcting an earlier mistake. Thus, among those who received a correction, expertise alone does not appear to influence whether people use the use or correction or continue to rely on the original information.

It is important to note that in our pre-study norming (which did not include participants from the actual study) our low credibility source (the politician's opponent) scored low on expertise and neutral on trustworthiness. In contrast, at the end of the study when participants rated the sources credibility, trustworthiness, and expertise, we found that participants rated the politician's opponent to be significantly higher in credibility than our high credibility source (prosecutor) and equal to the prosecutor on trustworthiness and expertise. During norming participants read the story without the correction and were asked to judge how credible, trustworthy, and expert the correction statement would be coming from a list of possible sources. The norming participants were exposed to the story material, however, after going through the entire experiment participants had more time to think about the sources' role in the story and doing so may have allowed them to see the political opponent as more credible. After all, the political opponent has nothing to gain from announcing that his opponent did not receive any bribe money; however, during norming, many participants may not be using the story context and instead judge all politicians as low in credibility. However, as mentioned, 
there were no significant differences in use of the original information on inference questions by participants post-test credibility ratings.

Finally, in Experiment 3 we held expertise constant and manipulated the sources trustworthiness. In this experiment we found that trustworthiness may be what is driving our effect. Results showed that when the source of the correction was high on trustworthiness it significantly decreased use of the original information, in comparison to the low trustworthy source.

This study adds to a growing number of studies examining the persistence of incorrect inferences in memory (Wilkes \& Leatherbarrow, 1988; Johnson \& Seifert 1994, 1999; Wilkes \& Reynolds, 1999; Guillory \& Geraci 2010). Previous research has shown that one promising method for correcting erroneous inferences is to give people a plausible alternative to the original information (Johnson \& Seifert, 1994). The current study suggests that when people are not given a plausible alternative, one way to reduce the lingering memory effects of erroneous inferences is to make the source of the correction more credible. This is important because in the real world, there may not always be an alternative explanation. Sometimes you may just need to negate the old information. This study suggests that an effective way to do this is if the correction comes from source that people consider credible, specifically trustworthy.

The first study of this kind to use a post-test questionnaire found that participants who believed the original information and thought that the correction was a cover up, were numerically but not statistically more likely to continue using the original information when answering inference questions (Guillory \& Geraci, 2010). In the 
current study, results from all three experiments showed that participants who believed the original information and thought that the correction was a lie indeed were statistically more likely to continue using the original information when making inferences. This finding is significant because it provides evidence for the claim that many people do not even believe the correction, and that is why they continue using the original information.

As mentioned in the introduction, research on jury's and courtroom behavior suggests that a jury's ability to disregard information may depend on the instruction to disregard information. For example, jurors appear to be able to disregard information if the reason given is compelling (Kassin \& Sommers, 1997). Their findings suggest that if a compelling reason is given for the correction, then people are more inclined to alter their initial beliefs. In another study using mock jurors, the authors proposed that giving jurors instructions or information that elicit suspicion of ulterior motives might allow them to be less influenced by non-evidentiary information to which they have been exposed (Fein, McCloskey, \& Tomlinson, 1997). Suspicion not only provides compelling reasons to discredit the information completely, but it also facilitates effective discounting (Fein, 1996; Fein, Hilton, \& Miller, 1990). The current study directly supports this finding/idea. When participants were made suspicious of the original information (high credibility correction) it significantly decreased the use of the original information when making inferences. Similarly, when participants were made suspicious of the correction (low credibility correction) they were significantly more likely to continue using the original information when making inferences. This finding 
was reinforced when looking at the paranoia data from the current study, which showed that when highly paranoid participants saw a correction from a high credibility source they were more likely to use the correction and believe that the original message was untrue, however when highly paranoid participants never received the correction message they relied on the original information even more than participants who showed lower levels of paranoia.

The current study has important implications when considering politics in today's society. Research has shown that negative (smear) campaigns depress the publics' evaluation of the political opponent (Fridkin \& Kenney; 2004, 2008). The results from the current study suggest that if a politician wants to clear up negative information that is being spread about him/herself, the correction or clarification, should come from someone who the public views as credible or trustworthy. 


\section{REFERENCES}

Ahluwalia, R., Burnkrant, R. E., \& Unnava, H. R. (2000). Consumer response to negative publicity: The moderating role of commitment. Journal of Marketing Research, 37(2), 203-214.

Baron-Cohen, S. (2009). Media distortion damages both science and journalism. New Scientist, 2701, 26-28.

Broeder, D. W. (1959). The University of Chicago jury project. Nebraska Law Review, 88, 744-760.

Cacioppo, J. T., \& Petty, R. E. (1982). The need for cognition. Journal of Personality and Social Psychology, 42(1), 116-131.

Chinn, C. A., \& Brewer, W. F. (1993). The role of anomalous data in knowledge acquisition: A theoretical framework and implications for science instruction. Review of Educational Research, 63(1), 1-49.

Fein, S. (1996). Effects of suspicion on attributional thinking and the correspondence bias. Journal of Personality and Social Psychology, 70(6), 1164-1184.

Fein, S., Hilton, J. L., \& Miller, D. T. (1990). Suspicion of ulterior motivation and the correspondence bias. Journal of Personality and Social Psychology, 58(5), 753-764. 
Fein, S., McCloskey, A. L., \& Tomlinson, T. M. (1997). Can the jury disregard that information? The use of suspicion to reduce the prejudicial effects of pretrial publicity and inadmissible testimony. Personality and Social Psychology Bulletin, 23(11), 1215-1226.

Fenigstein, A., \& Vanable, P. A. (1992). Paranoia and self-consciousness. Journal of Personality and Social Psychology, 62, 129-138.

Fiske, S. T. (1980). Attention and weight in person perception: The impact of negative and extreme behavior. Journal of Personality and Social Psychology, 38(6), 889906.

Fournier, S. (1998). Consumers and their brands: Developing relationship theory in consumer research. Journal of Consumer Research, 24(4), 343-373.

Fragale, A. R., \& Heath, C. (2004). Evolving informational credentials: The (mis)attribution of believable facts to credible sources. Personality and Social Psychology Bulletin, 30(2), 225-236.

Fridkin, K.L., \& Kenney, P.J. (2004). Do negative messages work? The impact of negativity on citizens' evaluations of candidates. American Politics Research, 32(5), $570-605$.

Fridkin, K.L., \& Kenney, P.J. (2008). The dimensions of negative messages. American Politics Research, 36(5), 694-723. 
Gallo, R.C. (2006). A reflection on HIV/AIDS research after 25 ears. Retrovirology, 3(72), 1-7.

García-Arista, E., Campanario, J. M., \& Otero, J. (1996). Influence of subject matter setting on comprehension monitoring. European Journal of Psychology of Education, 11(4), 427-441.

Gilbert, D. T., Fiske, S. T., \& Lindzey, G. (1998). The handbook of social psychology, Vols. 1 and 2 (4th ed.). New York: McGraw-Hill.

Golding, J. M., \& Hauselt, J. (1994). When instructions to forget become instructions to remember. Personality and Social Psychology Bulletin, 20(2), 178-183.

Gordon, R., Franklin, N., \& Beck, J. (2005). Wishful thinking and source monitoring. Memory \& Cognition, 33(3), 418-429.

Greenberg, B. S., \& Miller, G. R. (1966). The effects of low-credible sources on message acceptance. Speech Monographs, 33(2), 127-136.

Guillory, J. J., \& Geraci, L. (2010). The persistence of inferences in memory for younger and older adults: Remembering facts and believing inferences. Psychonomic Bulletin \& Review, 17(1), 73-81.

Herek, G. M. (1999). AIDS and stigma. American Behavioral Scientist, 42(7), 11061116. 
Herek, G. M., \& Capitanio, J. P. (1993). Public reactions to AIDS in the united states: A second decade of stigma. American Journal of Public Health, 83(4), 574-577.

Isbell, L. M., Smith, H. L., \& Wyer, R. S., Jr. (1998). Consequences of attempts to disregard social information. In J. M. Golding, \& C. M. MacLeod (Eds.), Intentional forgetting: Interdisciplinary approaches. (pp. 289-320). Mahwah, NJ: Lawrence Erlbaum Associates Publishers.

Johnson, H. M., \& Seifert, C. M. (1994). Sources of the continued influence effect: When misinformation in memory affects later inferences. Journal of Experimental Psychology: Learning, Memory, and Cognition, 20(6), 1420-1436.

Johnson, H. M., \& Seifert, C. M. (1999). Modifying mental representations: Comprehending corrections. In H. van Oostendorp, \& S. R. Goldman (Eds.), The construction of mental representations during reading. (pp. 303-318). Mahwah, NJ: Lawrence Erlbaum Associates Publishers.

Jost, J. T., Glaser, J., Kruglanski, A. W., \& Sulloway, F. J. (2003). Political conservatism as motivated social cognition. Psychological Bulletin, 129(3), 339-375.

Kassin, S. M., \& Sommers, S. R. (1997). Inadmissible testimony, instructions to disregard, and the jury: Substantive versus procedural considerations. Personality and Social Psychology Bulletin, 23(10), 1046-1054. 
Kassin, S. M., \& Studebaker, C. A. (1998). Instructions to disregard and the jury: Curative and paradoxical effects. In J. M. Golding, \& C. M. MacLeod (Eds.), Intentional forgetting: Interdisciplinary approaches. (pp. 413-434). Mahwah, NJ: Lawrence Erlbaum Associates Publishers.

Klein, J. G. (1996). Negativity in impressions of presidential candidates revisited: The 1992 election. Personality and Social Psychology Bulletin, 22(3), 288-295.

Kuklinski, J. H., Quirk, P. J., Jerit, J., Schwieder, D., \& Rich, R. F. (2000). Misinformation and the Currency of Democratic Citizenship. Journal of Politics, 62(3), 790-816.

Maheswaran, D., \& Meyers-Levy, J. (1990). The influence of message framing and issue involvement. Journal of Marketing Research, 27(3), 361-367.

Mannes, S. (1994). Strategic processing of text. Journal of Educational Psychology, 86(4), 577-588.

Petty, R. E., Briñol, P., \& Tormala, Z. L. (2002). Thought confidence as a determinant of persuasion: The self-validation hypothesis. Journal of Personality and Social Psychology, 82(5), 722-741.

Pickel, K. L. (1995). Inducing jurors to disregard inadmissible evidence: A legal explanation does not help. Law and Human Behavior, 19(4), 407-424. 
Ross, L., Lepper, M. R., \& Hubbard, M. (1975). Perseverance in self-perception and social perception: Biased attributional processes in the debriefing paradigm. Journal of Personality and Social Psychology, 32(5), 880-892.

Schul, Y. (1993). When warning succeeds: The effect of warning on success in ignoring invalid information. Journal of Experimental Social Psychology, 29(1), 42-62.

Seifert, C. M. (2002). The continued influence of misinformation in memory: What makes a correction effective? In B. H. Ross (Ed.), The psychology of learning and motivation: Advances in research and theory, Vol. 41. (pp. 265-292). San Diego: Academic Press.

Skowronski, J. J., \& Carlston, D. E. (1989). Negativity and extremity biases in impression formation: A review of explanations. Psychological Bulletin, 105(1), $131-142$.

Sue, S., Smith, R. E., \& Caldwell, C. (1973). Effects of inadmissible evidence on the decisions of simulated jurors: A moral dilemma. Journal of Applied Social Psychology, 3(4), 345-353.

Thompson, W. C., Fong, G. T., \& Rosenhan, D. L. (1981). Inadmissible evidence and juror verdicts. Journal of Personality and Social Psychology, 40(3), 453-463.

Triggle, N. (2010). MMR doctor struck off register. Retrieved from http://news.bbc.co.uk/2/hi/health/8700611.stm 
Tversky, A., \& Kahneman, D. (1973). Availability: A heuristic for judging frequency and probability. Cognitive Psychology, 5(2), 207-232.

van Oostendorp, H. (1996). Updating situation models derived from newspaper articles. Zeitschrift Für Medienpsychologie, 8(1), 21-33.

van Oostendorp, H., \& Bonebakker, C. (1999). Difficulties in updating mental representations during reading news reports. In H. van Oostendorp, \& S. R. Goldman (Eds.), The construction of mental representations during reading. (pp. 319-339). Mahwah, NJ: Lawrence Erlbaum Associates Publishers.

Wegner, D. M. (1994). Ironic processes of mental control. Psychological Review, 101(1), 34-52.

Wilkes, A. L., \& Leatherbarrow, M. (1988). Editing episodic memory following the identification of error. The Quarterly Journal of Experimental Psychology A: Human Experimental Psychology, 40A(2), 361-387.

Wilkes, A. L., \& Reynolds, D. J. (1999). On certain limitations accompanying readers' interpretations of corrections in episodic text. The Quarterly Journal of Experimental Psychology A: Human Experimental Psychology, 52A(1), 165-183.

Wissler, R. L., \& Saks, M. J. (1985). On the inefficacy of limiting instructions: When jurors use prior conviction evidence to decide on guilt. Law and Human Behavior, 9(1), 37-48. 
Wistrich, A.J., Guthrie, C., \& Rachlinski, J.J. (2005). Can judges ignore inadmissible information?: The difficulty of deliberately disregarding. University of Pennsylvania Law Review, 153, 1251-1345.

Zajonc, R. B. (2001). Mere exposure: A gateway to the subliminal. Current Directions in Psychological Science, 10(6), 224-228. 


\section{APPENDIX A}

\section{HENRY LIGHT RUNS FOR RE-ELECTION}

\section{Control Condition}

Message 1: On August $10^{\text {th }} /$ Henry Light announces his campaign for re-election.

Message 2: This is not a surprise to anyone/because he was a good politician/ and did many beneficial things for his state during his first term.

Message 3: In his campaign Henry Light promises to improve schools in underprivileged districts./ This is very important to him as he was underprivileged growing up.

Message 4: Henry Light embarks on a bus tour around the state to promote his campaign./During this time he meets with many of the local citizens.

Message 5: There are many secret meetings scheduled during the campaign./ No media are allowed in during the meetings.

Message 6: In the middle of his campaign,/it is reported that Henry Light was seen taking bribe money./

Message 7: Henry Light was raised by a single mother,/ with his 4 brothers and 3 sisters.

Message 8: From a young age Henry Light vowed that he would be successful as an adult,/ and never be poor again./ He wanted to give his mother and siblings what they never had growing up.

Message 9: Henry Light takes time away from his campaign to take a vacation with his wife and children./ During this time he does not speak with the media.

Message 10: Henry Light and his opponent meet to have a public debate about their stand on important issues./ The debate is televised on the local media station.

Message 11: Two months into his campaign/ Henry makes a sizeable donation to the homeless.

Message 13: Election day arrives on May $16^{\text {th }}$. 


\section{Experiment 1: Control Condition}

Message 12: The local school children follow the election coverage.

Experiment 1 (Credibility as a function of Expertise and Trustworthiness): High Credibility Condition

Message 12: An uninvolved federal judge reports a correction/ that the previous report was incorrect /and Henry Light did not take any bribe money.

Experiment 1 (Credibility as a function of Expertise and Trustworthiness): Low Credibility Condition

Message 12: One of the homeless men who received Henry's donation issues a correction/ stating that the previous report was incorrect /and Henry Light did not take any bribe money.

Experiment 2 (Credibility as a function of Expertise): High Credibility Condition

Message 12: A prosecutor reports a correction/ that the previous report was incorrect/ and Henry Light did not take any bribe money.

Experiment 2 (Credibility as a function of Expertise): Low Credibility Condition / Experiment 3 (Credibility as a function of Trustworthiness): High Credibility Condition

Message 12: Henry Light's political opponent reports a correction/ that the previous report was incorrect/ and Henry Light did not take any bribe money.

\section{Experiment 3 (Credibility as a function of Trustworthiness): Low Credibility} Condition

Message 12: Henry Light's wife reports a correction/ that the previous report was incorrect/ and Henry Light did not take any bribe money

(The units scored at Free Recall are indicated by /........) 


\section{APPENDIX B}

\section{REMEMBER/KNOW/BELIEVE INSTRUCTIONS}

\section{Remember}

You should make a remember judgment if you can consciously recollect its prior occurrence. Remember is the ability to become consciously aware again of some aspect or aspects of what happened or what was experienced at the time the report was presented (e.g. aspects of the physical appearance of the information, or of something that happened in the room, or of what you were thinking or doing at the time). In other words, the "remembered" information should bring back to mind a particular association, image, or something more personal from the time of study, or something about its appearance or position (i.e., what came before or after that message).

\section{Know}

You should make a know judgment if you recognize the information from the report, but you cannot consciously recollect anything about its actual occurrence or what happened or what was experienced at the time of its occurrence. In other words, write "know" when you care certain that you recognize the information, but it fails to evoke any specific conscious recollection from the study time.

\section{Believe}

When making a believe judgment you don't have to specifically recall the information, but you are indicating that you believe this particular information, it feels plausible, or you simply believe it to be true.

To further clarify the difference between these three judgments (remembering, knowing, and believing) here are a few examples. If someone asks you who was the first president of the U.S. you would typically respond in the "know" sense, without becoming consciously aware of anything about a particular event or experience of learning that information. When asked about the last movie you saw, you would typically respond in the "remember" sense that is, becoming consciously aware again of some aspects of the experience of seeing the movie. For example, you might remember where you sat, or that you were thinking. Alternatively, if someone asks you whether t.v. is bad for you, you may not recollect having learned about this issue and you may not know for sure. Rather you simply believe this to be true. 


\section{APPENDIX C}

\section{ITEMS ON THE PARANOIA SCALE}

1. Someone has it in for me.

2. I sometimes feel as if I'm being followed.

3. I believe that I have often been punished without a cause.

4. Some people have tried to steal my ideas and take credit for them.

5. My parents and family find more fault with me than they should.

6. No one really cares much what happens to you.

7. I am sure I get a raw deal from life.

8. Most people will use somewhat unfair means to gain profit or an advantage, rather than lose it.

9. I often wonder what hidden reason another person may have for doing something nice for you.

10. It is safer to trust no one.

11. I have often felt that strangers were looking at me critically.

12. Most people make friends because friends are likely to be useful to them.

13. Someone has been trying to influence my mind.

14. I am sure I have been talked about behind my back.

15. Most people inwardly dislike putting themselves out to help other people.

16. I tend to be on my guard with people who are somewhat more friendly than I expected.

17. People have said insulting and unkind things about me.

18. People often disappoint me.

19. I am bothered by people outside, in cars, in stores, etc. watching me.

20. I have often found people jealous of my good ideas just because they had not thought of them first. 


\section{APPENDIX D}

\section{ITEMS ON THE NEED FOR COGNITION SCALE}

1. I would prefer complex to simple problems.

2. I like to have the responsibility of handling a situation that requires a lot of thinking.

3. Thinking is not my idea of fun.*

4. I would rather do something that requires little thought than something that is sure to challenge my thinking abilities.*

5. I try to anticipate and avoid situations where there is likely a chance I will have to think in depth about something.*

6. I find satisfaction in deliberating hard and for long hours.

7. I only think as hard as I have to.*

8. I prefer to think about small, daily projects to long-term ones.*

9. I like tasks that require little thought once I've learned them.*

10. The idea of relying on thought to make my way to the top appeals to me.

11. I really enjoy a task that involves coming up with new solutions to problems.

12. Learning new ways to think doesn't excite me very much.*

13. I prefer my life to be filled with puzzles that I must solve.

14. The notion of thinking abstractly is appealing to me.

15. I would prefer a task that is intellectual, difficult, and important to one that is somewhat important but does not require much thought.

16. I feel relief rather than satisfaction after completing a task that required a lot of mental effort.*

17. It's enough for me that something gets the job done; I don't care how or why it works.*

18. I usually end up deliberating about issues even when they do not affect me personally.

*Indicates items that are reverse scored 
VITA

\author{
Jimmeka Joy Guillory \\ Texas A\&M University \\ Department of Psychology \\ College Station, Tx 77843-4235 \\ c/o Lisa Geraci \\ jimguillory44@gmail.com
}

EDUCATION

B.S., Psychology

May 2006

Texas A\&M University, College Station, TX

M.S., Psychology

May 2009

Texas A\&M University, College Station, TX

Ph.D., Psychology

August 2011

Texas A\&M University, College Station, TX

RESEARCH INTERESTS

Conscious Experiences of Memory, Inferences, Aging and Memory

RESEARCH EXPERIENCE

Graduate Researcher, Texas A\&M University, College Station, TX Aug 2006Aug 2011

Research Assistant, Texas A\&M University, College Station, TX Jan 2005May 2006

\title{
TEACHING EXPERIENCE
} Instructor, Texas A\&M University, College Station, Tx

Fall 2010May 2011

\section{PUBLICATIONS}

Guillory, J. J., \& Geraci, L. (2010). The persistence of inferences in memory for younger and older adults: Remembering facts and believing inferences.

Psychonomic Bulletin \& Review, 17(1), 73-81.

Geraci, L., McCabe, D. P., \& Guillory, J. J. (2009). On interpreting the relationship between remember-know judgments and confidence: The role of instructions. Consciousness and Cognition: An International Journal, 18(3), 701709. 